\begin{tabular}{|c|c|}
\hline Title & $\begin{array}{l}\text { Interface bond between FRP sheets and concrete substrates: properties, numerical modeling and roles in member } \\
\text { behaviour }\end{array}$ \\
\hline Author(s) & Ueda, Tamon; Dai, Jianguo \\
\hline Citation & $\begin{array}{l}\text { Progress in Structural Engineering and Materials, 7(1), 27-43 } \\
\text { https://doi.org/10.1002/pse.187 }\end{array}$ \\
\hline Issue Date & 2005-01 \\
\hline Doc URL & http:/hdl. handle.net/2115/5775 \\
\hline Rights & $\begin{array}{l}\text { Copyright @ } 2005 \text { John Wiley \& Sons, Inc., PROGRESS IN STRUCTURAL ENGINEERING AND MA TERIA LS, } \\
\text { Vol.7-1, p. 27-43 }\end{array}$ \\
\hline Type & article (author version) \\
\hline File Information & PSEM7-1.pdf \\
\hline
\end{tabular}

Instructions for use 


\title{
Interface bond between FRP sheets and concrete substrates - properties, numerical modeling and roles in member behaviors
}

\author{
Tamon Ueda ${ }^{(1)}$ and Jianguo Dai ${ }^{(2)}$ \\ ${ }^{(1)}$ Professor, Division of Structural and Geotechnical Engineering, Hokkaido University \\ Sapporo, Japan 060-8628 \\ ${ }^{(2)}$ Post-doctoral Fellow, Division of Structural and Geotechnical Engineering, Hokkaido University \\ Sapporo, Japan 060-8628
}

\section{SUMMARY}

The success of most of strengthening or retrofitting technologies for concrete structures by using external bonded FRP sheets highly depends on the interface bond between FRP sheets and concrete substrates. This paper reviews current studies on evaluating the bond properties of FRP sheet-concrete interfaces, and in particular, focuses on several newly developed bond models for describing the bond characteristics of FRP sheet-concrete interfaces under various loading conditions. This paper also gives several examples that apply those interfacial bond models to the design of different retrofitting cases. Analytical solutions are discussed that consider the local interfacial delamination and slip behaviour, which can improve the prediction of strength and deformation performances, as well as clarify the failure mechanisms of concrete members upgraded with FRP composites. Moreover, the improvement in structural performances of retrofitted concrete members is discussed by relating them to the optimum microscopic properties of the interface bond and the properties of retrofitting materials.

Key words: Fiber Reinforced Polymer (FRP), sheet bonding, interface bond, bond models, anchorage design, optimized interface properties

\section{INTRODUCTION}

With the development of the technology of upgrading the existing concrete structures by using externally bonded FRP composites, a number of issues related to conventional structural behaviors of the concrete structures after being upgraded have been studied in the past decade. Among them is a keen interest to clarify the mechanisms of the interface bond between FRP composites and concrete substrates, because the bonding interface is relatively weak in comparison with the neighboring materials in the whole upgraded system. In most of strengthening cases, the interface bond is critical in transferring stresses from 
the existing concrete structures to the externally bonded FRP composites. When a structural element is encircled in FRP composites the mechanical role of interface bond becomes less important, but it still has the function of keeping the integrity and durability of the composite FRP-concrete systems. Therefore, a good understanding on the interface bond is a prerequisite for achieving more reliable but rational design for concrete structures externally bonded with FRP composites.

Generally, there are two interface bonding systems for FRP upgrading, namely plate bonding and sheet bonding. A higher quality control is possible with FRP plate bonding system, compared with the sheet bonding system that has a greater potential for construction flaws, because the mixing of resins and the curing of FRP composites are carried out in field conditions. Kaiser and Karbhari [1,2] has given a detailed summary of the potential flaws that can occur during preparation of the concrete surface, of the adhesive and of the FRP composites, as well as of the whole bonding procedures, with a view to improving the quality control and monitoring of the bonding process. The sheet bonding system is currently more popular, because it has high conformability to the surface onto which sheet is bonded and offers maximum flexibility and convenience for construction. Current applications of the sheet bonding system include flexural strengthening, shear strengthening and column wrapping. In the column wrapping case, the interface bond failure is not a major concern. Instead, the fracture of FRP sheets is the dominant failure mode, and it has been recently suggested that FRP materials with a high fracture strain capacity (elongation larger than 5\%) can be used [3-5]. However, for concrete members strengthened with FRP sheets for flexure and shear, debonding of the FRP from concrete substrate can lead to overall structural failures (see Figures 1 and 2). In the shear strengthening cases, the debonding of FRP sheets from the concrete substrates are similar to those observed in pull-out shear bond tests. In the flexural strengthening cases, the debonding modes are various, and the corresponding failure mechanisms are more complex. Besides the conventional concrete compression failure or FRP fracture, the failure modes of FRP upgraded concrete members in flexure have been well documented in many literatures [6-9]:

(1) Plate-end failure (also called concrete cover delamination), which is a very brittle failure manner and arises from the normal and shear stress concentrations occurring at the ends of FRP near supports. Because this debonding leads to a catastrophic failure of the strengthened concrete members, its failure mechanisms have been heavily studied in the past decade [10-19]. The main reasons leading to this failure are the distance between the ends of the FRP and the beam supports 
and the use of relatively thick FRRP plates. However, when sheet bonding system is used, plate-end failure has not been widely reported, because FRP sheets are think and are usually extended to the supports.

(2) Anchorage failure, which is due to the insufficient anchorage length of FRP sheets.

(3) Mid-span debonding, where the interface debonding initiates from the tips of mid-span flexural cracks or flexural-shear cracks of RC members. To avoid the mid-span debonding failure, most present design guidelines recommend limits on the strains in the FRP sheets, although their approaches for determining these limits may be different $[8,9,20]$. Mid-span debonding results from the interaction of the steel reinforcement, concrete cover and the FRP sheets. So it is closely related to bond between steel reinforcement and concrete, crack spacing, dowel action on the FRP sheets, and, most of all, the interface slip and delamination behaviours between the FRP sheets and the concrete substrates. For the sheet-bonding system, mid-span debonding is a critical failure mode. .

To date, it can be said the macro-mechanical behaviour of RC members upgraded with FRP sheet, such as the fundamental failure modes and their effects on the strength capacity and ductility, have been well established, based on a large number of experimental and analytical studies in the past decade. However, to achieve a refined design for concrete structures to be upgraded with FRP sheets, further study is needed on the fundamental issues, such as interfacial bond fracture mechanisms, selection of bonding or strengthening material, and design detailing. For reliable, but rational and cost-effective use of FRP materials refined upgrading designs should follow performance-based design concepts, for which the accuracy of predicting the performances of FRP upgraded concrete members relies on accurate material laws, as well as advanced analytical methods.

The Japan Concrete Institute (JCI) established a technical committee on retrofitting technology (2001 to 2003) that focused on the interface bond properties between existing concrete structures and retrofitting materials for both adhesive bonding and overlaying retrofitting technologies [21]. The objective of the committee was to gain insight into the micro- and macro-interfacial bonding mechanisms, the selection of the optimum interface materials and upgrading methods, the improved prediction of the performances of upgraded concrete structures, and, finally, the improvement of current upgrading techniques from both a construction and material point of view. This paper also reflects part of achievements of this technical 
committee related to the interface bond between FRP sheets and concrete substrate.

In general, the research topics on the FRP sheet-concrete interfaces can be addressed by the following: :

1. Parametric studies on interface bond, which include effects of all interface components: concrete, bonding layer and FRP sheets;

2. Test method for evaluating the interface bond properties;

3. Bond strength and anchorage design;

4. Failure mechanisms of interface bond and bond modeling;

5. Effects of interface bond on member behavior of concrete structures after retrofitting;

6. Optimized design of interface bond; and

7. Durability of interface bond.

This paper focuses mainly on the interface bond, including its evaluations, modeling and influence on member behaviour of FRP upgraded concrete structures from point of view of mechanics. It should be mentioned that durability of interface bond is another very important issue, which is the focus of a technical committee of RILEM.

2. REVIEW ON THE FUNDAMENTAL BOND PROPERTIES OF FRP SHEET-CONCRETE INTERFACES AND THE EVALUATION METHODS

\subsection{Bond of FRP Sheet-Concrete Interfaces under Shear}

The most important role of the bond interface between FRP sheets and concrete is to transfer shear stresses from existing concrete structures to externally bonded FRP sheets for both shear strengthening and flexural strengthening cases (see Figs 1,2). Therefore, the shear bond properties of FRP sheet-concrete interfaces have been extensively studied. Various test methods including single-lap-type, double-lap-type, bending-type, and inserted-type (see Figs 3-6) have been developed to characterize the local interfacial shear bond behaviors by studying the strain distribution in the FRP sheets or to evaluate the average interfacial bond strength. The evaluated interface characteristic parameters include average shear bond strength, effective bond length, maximum shear bond stress, interfacial fracture energy, as well as the local bond stress-slip relationship. All studied experimental parameters can be summarized as shown in Table 1.

Bond length of FRP sheets [22-27] 
Many researchers have studied the effects of sheet bond length. While bond strength increase as the sheet bond length is increase, when the sheet bond length is increases beyond a certain extent, the bond length does not increase any further. Therefore, the average bond length decreases with the increase of sheet bond length. In other words, there exists an effective bond length. Besides the premature debonding phenomenon caused by shear stress concentration, the existence of effective bond length is another factor that causes the tensile strength of FRP materials not to be fully utilized. Nevertheless, owning the different definitions given by different researchers and the dissimilar materials used in their tests, the effective bond lengths can vary significantly, such as $45 \mathrm{~mm} \quad$ [22], $75 \mathrm{~mm}$ [23], $100 \mathrm{~mm}$ [24], $93 \mathrm{~mm}$ [25], 63.5 134.5 $\mathrm{mm} \mathrm{[26]} \mathrm{and} 275 \mathrm{~mm}[27]$.

- Bond width of FRP sheets [28-29]

It has been shown that the sheet width does not influence the average bond strength of interfaces when the width of sheets ranges from $50 \mathrm{~mm}$ to $200 \mathrm{~mm}$. However, when the sheet bond width is less than $50 \mathrm{~mm}$, the smaller the sheet width, the higher average shear bond strength that the interface can achieve.

Stiffness of FRP sheets

There are many reports on the effects of the stiffness of FRP sheets (elastic modulus $\times$ thickness). Clearly, the bond strength increases with the stiffness of FRP sheets. Meanwhile, a higher FRP stiffness will result in s longer anchorage length.

- Strength of concrete [25-26, 28-32]

Concrete strength is thought to be a factor affecting the interface bond significantly. But it is, in fact, rather difficult to verify its effects in experimentally. Only when the concrete strength is greatly can can its effects become visible. Yoshizawa et al. and Lorenzis et al. indicated that the dependence of the interfacial fracture energy on the concrete compressive strength $f_{c}^{\prime}$ is negligible $[25,30]$. However, Chajes et al. and Horiguchi reported that the bond strength is proportional to $f_{c}^{1 / 2}$ and $f_{c}^{12 / 3}$, respectively [31,32]. Brosens et al. reported that the bond strength is proportional to the square root of concrete tensile strength [28]. Nakaba et al. and Sato et al. reported that the maximum interfacial bond stresses are proportional to $f_{c}^{.0 .19}$ and $f_{c}^{10.20}$, respectively [26, 29].

Surface treatment of concrete

Test results by Chajes et al showed that surface preparation of the concrete influences the bond strength. 
They found that the using by mechanical abrading (similar to sandblasting) higher average interfacial bond strength could be achieved [31]. Mitsui et al. conducted a further quantitative study on the effects of surface condition. They evaluated the surface roughness index of concrete by changing the treatment methods, which were sandpaper polishing, disk sander grinding, sandblasting and chipping. They observed the three-dimensional profile of the concrete surface, using an optical displacement meter and obtained measurements of the maximum depth, superficial area and so on [33]. They concluded that the methods of sandblasting and chipping could lead to higher bond strength. Regarding the effects of concrete surface cleanness, it has been confirmed that the bond strength will decrease markedly if the concrete surface is greasy. But whether or not the moisture of concrete surface affects the bond strength or not depends on the type of bonding adhesives used. It should be noted that in practice it is difficult to control the roughness of concrete surface quantitatively. Experimental database, shown later herein, indicates that there is a wide scatter of bond strength caused by concrete surface condition, even when different workers (laboratories) follow a same surface treatment method. But as a minimum, a clean concrete substrate with open pore structures is needed to achieve a good bond between the adhesive and concrete, or, in other words, to ensure that the bond failure occurs in the concrete.

Properties of bond layers [34-35]

It has been found that bond layers with lower elastic moduli, but good ductility, can lead to higher interface bond strengths. The mechanical properties of bond layers can be adjusted through changing the elastic modulus of either bonding resin or putty. However the effective bond length increases when the elastic modulus of bond layers decreases. It was also reported that using ordinary primer with a viscosity of 2,000 mPa.s is better than using high permeability primer with a viscosity of $90 \mathrm{mPa}$.s. The latter primer leads to lower bond strength.

- Interface defects [21]

The lifting of bonded sheet can simulated the interface defects that can be induced during bonding construction. It has been reported that a $12 \times 12 \mathrm{~mm}$ lifting area of FRP sheets in specimens prepared for pull-out shear bond tests, which was equivalent to $6 \%$ to $13 \%$ of the whole sheet bonding area, has no significant effects on the overall pull-out bond strength.

\subsection{Bond of FRP Sheet-concrete Interfaces under Tension}

In comparison with shear bond test, tensile tests for FRP sheet-concrete interfaces are easier to perform 
in order to verify the interface bond quality. Three types of tensile test methods have been reported in the past (Figs 7-9). Fig.7 shows a direct tensile test method, which is adopted by the "Guideline on Upgrading of Concrete Structures with FRP sheet" of Japan Society of Civil Engineering (JSCE) and the "Design and Construction Guideline of Continuous Fiber Reinforce Concrete Structures" of Architectural Institute of Japan (AIJ). This method is convenient because it checks the interface bond quality qualitatively, by observing, for example, whether or not the fracture has occurred in the concrete. Figs 8 and 9 are three-point bending and wedge splitting, tests respectively [36-38]. They can be used to evaluate the Mode I fracture energy, as well as the tension softening diagram of FRP sheet-concrete interfaces. Based on the two test methods, the bond properties of FRP sheet-concrete interfaces under tension can be discussed parametrically and quantitatively. It was reported that under static loading condition and ordinary environmental condition, the Mode I fracture energy of FRP sheet-concrete interface is mainly affected by the concrete surface condition, e.g. whether or not the coarse aggregates have been exposed sufficiently. The selection of adhesives has a minor role, because the ashesives are more critical in shear than in tension. A three-point bending test has also been used for evaluating the bond degradation of FRP sheet-concrete interfaces after exposure to severe environmental and fatigue loading [39].

\subsection{Bond of FRP Sheet-Concrete Interface under Combination of Shear and Tension}

A more representative interface bond failure for concrete structures retrofitted with FRP should be a combined mode, recognizing that the FRP sheet-concrete interfaces are subjected to shear and tension simultaneously. Few experimental and analytical studies have been performed to evaluate the interface failure under mix-mode loading conditions. Karbhari and Engineer developed a bond test method to evaluate the bond between FRP composites and concrete under mix-mode loading conditions by producing different interface peeling angles [40]. However, their main purpose was to enable the determination of both Mode I (tension) and Mode II (shear) components of interfacial fracture energy and to allow a quantitative comparison of interface adhesion mechanisms and energies. They did not orientate their studies to any particular application of FRP strengthening technology for concrete structures.

There is a new application of FRP strengthening technology in Japan, which is to bond FRP sheets on the bottom surface of tunnel linings or elevating bridges for the purpose of preventing deteriorated concrete 
blocks from falling. In those strengthening cases, FRP sheet-concrete interfaces are under mix-mode loading, as shown in Fig.10. Two types of test methods have been applied to determine the bond properties of interfaces under these loading conditions [41-43]. One is beam-type dowel test for FRP sheet-concrete interfaces, in which one-directional FRP sheets are bonded on the bottom of a notched concrete beam (see Fig.11). The other is a slab-type shear punching test, in which bidirectional, rather than unidirectional FRP sheets are attached on the bottom of a concrete slab (see Fig.12). Two fundamental bond characteristics of FRP sheet-concrete interfaces under the dowel action have been obtained from both two test types: (1) the peeling angle (see Fig.10) is constant during the interface debonding procedure; and (2) the vertical force per unit width FRP sheet-concrete interface can bear is a constant value during the interface debonding procedure. The two conclusions can be used for bond modeling and retrofitting design, as shown in the following sections. Also, the analysis in the later part shows the outcomes from both two test methods are equivalent.

Another widely reported mix-mode failure mode of FRP sheet-concrete interface is in FRP strengthened RC beams in flexure $[6,9,44-45]$. The interface debonding may initiate from the tip of a shear-flexural crack, where the peeling is caused simultaneously by crack opening in longitudinal direction and crack sliding in vertical direction. Up to now no appropriate bond model has been published to describe this mix-mode failure, nor its associated design detailing. In general, this failure mode may be suppressed by limiting diagonal cracking, which in turn may be achieved through shear strengthening with transverse strips [8]. During experimental tests of RC beams flexurally strengthened with FRP sheets, it is difficult to measure the vertical sliding of a flexural-shear crack or the dowel deformation acting on FRP sheets. Consequently, whether or how much the vertical sliding of crack affects the flexural strengthening efficiency of FRP sheets is not clear. In the author's laboratory, experiments were performed to investigate whether or not the flexural strengthening efficiency of FRP sheets is affected by the ratio of transverse reinforcements. Two RC beams flexurally strengthened with same amount of FRP sheets were designed to fail in flexure. Steel stirrups were over-provided for both two beams, but in different ratios. Test results indicated that the strengthened RC beam with a larger amount of transverse reinforcements achieved about $10 \%$ higher flexural capacity than the other beam. and also showed better ductility, although both beams failed in flexure due to debonding of FRP sheets [46]. Therefore, the effects of 
mix-mode failure of FRP sheet-concrete interface are influenced by the amount of transverse reinforcement, and should be considered in a refined design.

It is clear that the contribution of the interface dowel resistance to the shear capacity of strengthened RC beams is negligible. However, the dowel action on FRP sheets may affect the efficiency of shear stress transfer in FRP sheet-concrete interface and result in a premature interface debonding, and, consequently, a decrease of the maximum tensile stress achieved in FRP sheets. To determine the effects of dowel action on the interface shear force transfer in the anchorage area, the authors performed mix-mode tests for the FRP sheet-concrete interfaces. In the tests, a dowel force was directly imposed onto FRP sheets through a vertical bar connected to the loading system of a universal test machine, which is similar to that in Fig.11. However, by setting a reaction framework inside the test machine, as shown in Fig.13, a pullout force could be introduced into FRP sheets, as well as a bending force on the concrete beams can be achieved by adding the dowel force and bending load simutaneously [47].

In the experiments, two layers of FRP sheets (FRP stiffness is $50.6 \mathrm{kN} / \mathrm{mm}$ ) were attached to concrete beams with an anchorage length of $400 \mathrm{~mm}$. Fig. 14 shows the effects of the overall flexural strengthening efficiency of dowel forces imposed on FRP sheets. The flexural strengthening efficiency is defined as the ratio of the maximum bending load a concrete beam achieved under dowel effects to that a reference beam achieved without the dowel effect. It has been found that the flexural strengthening efficiency is not significantly affected, even if the dowel force is added till the $90 \%$ of the interface dowel force capacity. In other words, if the dowel force locally imposed on FRP sheets does not exceed the interface dowel force capacity, its affects on the overall shear force transfer of the interface are not significant. As shown in the next section, the dowel force acting on FRP sheets is in fact the vertical component of tensile force in FRP sheets during the interface debonding. In order to decrease the dowel force while achieve a high tensile stress (flexural strengthening efficiency) in FRP sheets, the peeling angle between the concrete surface and FRP sheets should be controlled. Fig.15 shows the change of interface crack mouth open displacement (interface CMOD) between the FRP sheets and the concrete at the location where the dowel force was added with the increase of bending loads. It can be seen that the CMOD decreases with the increase of bending force, meaning that the increase of tensile stress in FRP sheets can be achieved by limiting the interface opening displacement in vertical direction if anchorage length is not sufficiently long. On the other side, if the CMOD, which equals the dowel deformation induced by diagonal cracks in 
an FRP strengthened beam, is fixed, the negative effects of dowel deformation on the flexural strengthening efficiency can be eliminated by increasing the additional anchorage length, which can consequently decrease the interface peeling angle.

In the experiments, the authors also monitored the bending loads corresponding to the initial debonding of the FRP sheets from the concrete substrates near the location where the dowel force was added (see

Fig.14). It can be seen the initiation of the interface debonding is significantly affected by the dowel force imposed. Although this kind of local debonding does not affect the ultimate shear force transfer capacity of an FRP sheet-concrete interface, as already discussed, the stiffness of strengthened concrete beams has been found to decrease by $20 \%$ when $90 \%$ of the maximum dowel force that the interface can bear was applied to FRP sheets compared with the stiffness of the reference beam.

\section{BOND MODELING AND FUNDAMENTAL APPLICATIONS IN RETROFITTING}

\section{ENGINEERING}

\subsection{Modeling for Interface Bond under Shear}

The bond stress-slip $(\tau \sim \mathrm{s})$ relationship is the most important law to describe the interface performance of two bonding materials. A number of $\tau \sim$ S relationships have been proposed by different researchers. However, even the shapes those $\tau \sim$ s relationships for FRP sheet-concrete interfaces differ greatly. For example, many configurations for the $\tau \sim$ s relationships, including cut-off type, bilinear type, elasto-plastic type, and Popovic type have been reported [22, 25-26, 29-30]. Those differences indicate the difficulty in defining a reliable local $\tau \sim \mathrm{S}$ model for an FRP sheet-concrete interface from conventional pull-out bond test results. The reasons may be as follows. First, the effective bond length of FRP sheet-concrete interfaces is rather short, and it is difficult to arrange many strain gages in an active, but short, load transfer length. Second, the FRP sheets have rather small bending stiffness, so that the strains observed on the surface of FRP sheets have a larger scatter due to local bending deformations. Third, the interface between FRP composites and concrete easily exceeds the peak shear bond stress, even if there is a low tensile stress level in FRP sheets, so the interfacial $\tau \sim$ s relationship is highly nonlinear [48].

To solve those difficulties, the authors developed a new differential solution for deriving the local $\tau \sim S$ constitutive law for an FRP sheet-concrete interface [49]. Based on that solution, it is not necessary to record the local bond behaviors of an FRP sheet-concrete interface during a pullout bond test. Instead the 
local $\tau \sim$ s relationship can be derived from the relationship between the pullout loads and slips at the point of loading. The proposed local $\tau \sim$ s relationship has two parameters, one of which is the interface fracture energy and another is interfacial ductility factor. Its expression has been obtained based on a lot of experimental results as follows:

$$
\tau=2 B G_{f}(\exp (-B s)-\exp (-2 B s))
$$

where $G_{\mathrm{f}}$ is the interfacial fracture energy $(\mathrm{N} / \mathrm{mm})$; $B$ is termed as interfacial ductility factor by the authors $\left(\mathrm{mm}^{-1}\right) . \mathrm{G}_{\mathrm{f}}$ and $\mathrm{B}$ have been determined through regression of the experimental data as follows:

$$
\begin{aligned}
& G_{f}=0.446\left(G_{a} / t_{a}\right)^{-0.352} f_{c}^{0.236}\left(E_{f} t_{f}\right)^{0.023} \\
& B=6.846\left(E_{f} t_{f}\right)^{0.108}\left(G_{a} / t_{a}\right)^{0.833}
\end{aligned}
$$

where $E_{f} t_{f}$ is the stiffness of FRP $(\mathrm{kN} / \mathrm{mm}) ; \mathrm{G}_{\mathrm{a}}$ is the shear modulus of adhesive bond layer (GPa); $t_{\mathrm{a}}$ is the thickness of adhesive bond layer $(\mathrm{mm})$; and $\mathrm{f}_{\mathrm{c}}$ ' is the compressive strength of concrete (MPa).

The proposed $\tau \sim$ s relationship can consider the effects of all interfacial components: stiffness of FRP, concrete and adhesive. One advantage of this above $\tau \sim$ s relationship is its simplicity on expression and the rigorous analytical procedure. Another advantage is that parameters such as the peak bond stress and the corresponding slip value, which in fact are difficult to be calibrated during pull-out tests, can be determined mathematically as follows:

$$
\begin{aligned}
s_{\text {max }} & =0.693 / B \\
\tau_{\text {max }} & =0.5 B G_{f}
\end{aligned}
$$

For most of the frequently used adhesives, Equation 1 can be further simplified by averaging a lot of experimental curves and neglecting the minor effects caused by stiffness of FRP as shown in Figure 9. Then the Equation 1 becomes:

$$
\tau=10.7 f_{c}^{0.236}(\exp (-10.4 s)-\exp (-20.8 s))
$$

\subsection{Anchorage Design for Tensile Force in FRP sheets}

A fundamental issue in studying the shear bond between concrete and any reinforcing material is the anchorage design. The bond of externally bonded FRP sheets to concrete is significantly different from that of reinforcing bars in concrete. The anchorage design criteria for the bond of reinforcing bars in RC 
is to guarantee a sufficient development length, with which a reinforcing bar can resist a tensile force equal to its tensile strength. However, the externally bonded FRP in an FRP sheet-concrete interface seldom can reach its material strength, even over a very long bond length, because of the existence of premature debonding and effective bond length, as reviewed in Section 1. Therefore, the problem of how to precisely determine precisely the full interfacial bond strength at debonding and the necessary effective bond length to achieve that bond strength should be solved. Until now, a number of empirical and analytical models related to average bond length, effective bond length have been proposed in the past $[9,30,50-53]$. However, most of the existing effective bond length models consider only the effects of FRP stiffness and concrete strength and neglect the important effects of the interface adhesives, which significantly affect the effective bond length and the bond strength [34]. In addition, the effective bond length is usually used in existing bond strength models as a parameter to predict the bond strength of an FRP sheet-concrete interface by judging whether or not its bond length is longer than the effective bond length [50-53]. However, as reviewed in Section 2.1, the effective bond length was reported in a widely scattered range of $45 \sim 275 \mathrm{~mm}$. Indeed, a more reasonable and general approach is to determine the anchorage length based on the bond stress-slip relationship obtained. On the basis of $\tau \sim \mathrm{s}$ relationship, as shown in Equation 1, the authors developed a model for predicting the anchorage length of FRP sheet-concrete interfaces by analyzing the strain distributions in FRP sheets and the bond stress distribution along the interface [54]. Figure 17 show an example of the predicted shear stress distributions of an FRP sheet-concrete interface under different pull-out loading levels. It can be seen that there exists only a limited distance with visible bond stresses, even a very long length is available. That is why FRP sheet-concrete interfaces cannot increase their bond strength beyond the effective bond length. Consequently, the effective bond length can be defined as that active bond distance $\mathrm{L}_{\mathrm{e}}$ indicated in Figure 17, which can be expressed mathematically as follows:

$$
L_{e}=\frac{\sqrt{2 E_{f} t_{f}}}{B \sqrt{G_{f}}} \ln \left(\frac{1+\alpha}{1-\alpha}\right)
$$

where $L_{e}$ is the effective bond length, $\alpha$ is the ratio of the bond force that the effective bond area can bear to the defined theoretical maximum bond strength. Theoretically there always exists even a tiny shear stress between the FRP and concrete no matter how big the interfacial slip becomes, meaning that the interface can never achieve the maximum theoretical bond strength ( $\alpha$ always smaller than 1.0). Based on 
experimental observations $\alpha$ can be taken as 0.96 for the purpose of anchorage design.

The proposed expression for effective bond length $L_{e}$ can include the effects of concrete, FRP stiffness and the adhesive layer as well. The $\mathrm{L}_{\mathrm{e}}$ increases with the stiffness of FRP, but decreases with the increase of interfacial fracture energy and the B. The B has a higher value when a stiffer adhesive is used and vice versa. By using a similar solution, a unified bond strength model for FRP sheet-concrete interfaces, which was derived from Equation 7, was also developed as follows [54]:

$$
\begin{aligned}
& P_{u}=\alpha P_{\max } \\
& \alpha=\frac{\exp \left(\frac{L_{b} B \sqrt{G_{f}}}{\sqrt{2 E_{f} t_{f}}}\right)-1}{\exp \left(\frac{L_{b} B \sqrt{G_{f}}}{\sqrt{2 E_{f} t_{f}}}\right)+1} \\
& P_{\max }=\left(b_{f}+2 \Delta b_{f}\right) \sqrt{2 E_{f} t_{f} G_{f}}
\end{aligned}
$$

Where $P_{u}$ is the bond strength of FRP sheet-concrete interface with a given bond length $\mathrm{L}_{b} ; \mathrm{L}_{b}$ is the bond length of FRP sheets; $\triangle b_{f}$ is an additional width, which is given to consider the effects of bond width of FRP sheets on the average interface bond strength and can be taken as $3.7 \mathrm{~mm}$ based on test results [29]. Another important issue that should be mentioned is the large scatter of bond strength. The bonding performances of FRP sheet-concrete interfaces closely rely on the concrete properties. However, the bond strength of FRP sheet-concrete interfaces is in fact more sensitive to the condition of concrete surface preparation, because the bond failure always happens within a thin concrete layer just beneath the adhesive. Even though a standard concrete surface treatment is followed, the concrete surface condition may deviate according to the operating skills of the workers. At present, it is difficult to quantify scientifically and precisely these construction deviations of concrete surface conditions. Also, the bond performances achieved in construction are not easily obtained because pull-out bond tests are less likely to be performed after a concrete structure has been strengthened. However, the accumulation of experimental databases of pullout test results in laboratories to date makes it possible to evaluate statistically the effects of construction deviations on the bond strength.

The authors collected a large number of pull-out bond test results for FRP sheet-concrete interfaces (220 specimens), which were published by 11 researchers [22-31, 55-56]. Figure 18 gives a comparison 
between all test results and the analytical predictions of the present bond strength model. It shows that the scatter of the bond strength of FRP sheet-concrete interfaces is rather large, though the present model gives a good average prediction. After the other material factors are considered appropriately, the remaining large scatter can be considered as a kind of construction deviation. Therefore, for a safe interface bond design, a construction deviation factor can be introduced to the present model.

According to the databases shown in Figure 18, a reduction factor 0.68 can be added in the present bond strength model (Equations 8.1 to 8.3 ) if we permit that $5 \%$ of the experimental data (the points above the dotted line $P_{\text {pre. }} / P_{\text {ana. }}=1.5$ in Fig.18) can be overestimated. According to the square root relationship between the ultimate pullout load and interfacial fracture energy, a construction deviation factor of $k_{c}=0.46$ can be considered in the expression for the $G_{f}$ (Equation 2 ) for engineering design purpose. With this approach, the anchorage length is given a safety factor of 1.46 based on the relationship between $\mathrm{L}_{\mathrm{e}}$ and $\mathrm{G}_{\mathrm{f}}$ as shown in Equation 7. Figure 18 also includes test data of several FRP plate-concrete interfaces, for which FRP has a high tension stiffness (about $200 \mathrm{kN} / \mathrm{mm}$ ). It is shown that the analytical model proposed, based on sheet bonding system, always overestimates the bond strength of FRP plate-concrete interfaces, implying that sheet bonding system can achieve higher interfacial fracture energy than the plate bonding system. A possible explanation for this is that FRP sheets have greater conformability to the concrete surface irregularity.

\subsection{Modeling for Interface Bond under Tension [38]}

In general, the fracture of FRP sheet-concrete interfaces occurs in concrete, because the tensile strength of adhesive is usually higher than that of concrete. The thickness of concrete over which the damage occurs is small in comparison with the dimensions of the whole concrete element. So the interface debonding can be simulated as the interfacial cracking, using link elements between FRP and concrete, as shown in Figure 19. The nonlinear damage in the concrete element can be simulated by lumping it into the softening of the interface element instead of allowing damage in the concrete elements. The crack open displacement of interface is a combination of the cracking in the adhesive layers and concrete, respectively, before and after the peak tensile stress of concrete is reached. So the interface tensile stress-open displacement relationship can be expressed as follows: 


$$
\begin{aligned}
& \sigma=k \delta \quad\left(\delta \leq \delta_{p}, \delta_{p}=\frac{f_{t}}{k}\right) \\
& \sigma=f(\delta)\left(\delta_{p}<\delta<\delta_{u}\right) \\
& \sigma=0 \quad\left(\delta>\delta_{u}\right)
\end{aligned}
$$

where $\mathrm{k}$ is the initial elastic stiffness of interface spring $\left(\mathrm{N} / \mathrm{mm}^{3}\right)$. $\delta$ is the interface opening displacement $(\mathrm{mm}) ; \delta_{\mathrm{p}}$ is the interface opening displacement at peak stress $(\mathrm{mm})$ and $\delta_{\mathrm{u}}$ is the interface open displacement corresponding to zero cohesive stress (mm).

To get the tension softening diagram of FRP sheet-concrete interfaces $\sigma=f(\delta)$, the authors performed conventional three-point bending tests on notched composite beams, which included FRP sheet-concrete interfaces as shown in Fig.8. Both concrete and mortar substrates were prepared for bonding FRP sheets. Cyclic loading way was applied on all composite beams and the interface tension-softening diagram was derived through improved J-integral method and then verified through FEM analysis. Figure 20 shows the experimental relationships between the interfacial tensile stress and the open displacement for concrete and mortar bonding substrates, respectively. It was found that a following unified expression could model the observed interfacial tension softening diagrams quite well.

$$
\sqrt[\alpha]{\sigma / f_{t}}+\sqrt{\delta / \delta_{u}}=1
$$

where: $\alpha$ is an interface ductility index, which can be taken as $2.2 \sim 2.5$ and 3.0 for concrete and mortar bonding substrates respectively. $\delta_{u}$ can be taken as $0.3 \mathrm{~mm}$ for both concrete and mortar bonding substrates in the case of using normal bonding adhesives (the elasticity modulus of bonding adhesive $E_{a}$ is higher than 1.0GPa).

Load-deflection curves of notched composite concrete beams can be derived, and include the FRP sheet-concrete interface elements between two concrete blocks (see Fig.8) in the FEM analysis. From these curves, the value of $E_{a} / t_{a}$ can be used to determine the initial elastic stiffness $\mathrm{k}$ of interface spring, where $\mathrm{E}_{\mathrm{a}}$ is elastic modulus of used bonding adhesives and $t_{a}$ can be measured.experimentally.

\subsection{Modeling for Interface Bond under Dowel Action}

I do not think that ta values are necessary to be shown. Thanks for the rectification

As mentioned in Section 2.3, the FRP sheet-concrete interfaces may fail under dowel action, in which 
case the FRP sheet-concrete interfaces bear tension and shear effects simultaneously. As shown in the Fig.10, the interface debonding under dowel action is governed by the component of tensile force $T$ in FRP sheets in the direction of dowel deformation. If the force induced by a given dowel deformation exceeds the dowel force capacity of an FRP sheet-concrete interface, the dowel will fail. Therefore, to avoid this kind of dowel failure, it is important to be able to predict the interface dowel force capacity. In the loading condition shown in Figure 10, the dowel force acting on the FRP sheet-concrete can be approximately expressed as follows:

$$
\begin{aligned}
& \varepsilon_{f}=\left(\frac{1}{\cos \theta}-1\right) \\
& \frac{P_{d}}{b_{f}}=2 E_{f} t_{f} \varepsilon_{f}=2 E_{f} t_{f} \cdot\left(\frac{1}{\cos \theta}-1\right) \cdot \sin \theta
\end{aligned}
$$

where $\varepsilon_{\mathrm{f}}$ is the tensile strain in the FRP sheets. $\mathrm{P}_{\mathrm{d}}$ is dowel force imposed on the FRP sheets; T is tensile stress in the FRP sheets; $\mathrm{E}_{\mathrm{f}} \mathrm{t}_{\mathrm{f}}$ is the tension stiffness of the FRP sheets; $b_{f}$ is the bond width of the FRP sheets; and $\theta$ is the interface peeling angle.

From a series of dowel tests as shown in Fig.11, the authors derived the relationship between the critical peeling angle and the spalling fracture energy of an FRP sheet-concrete interface under a dowel force as follows [43]:

$$
G_{f s}=E_{f} t_{f}\left[\frac{(1-\cos \theta)\left(\sin ^{2} \theta-\cos ^{2} \theta+\cos \theta\right)}{2 \cos ^{2} \theta}\right]
$$

where $G_{f s}$ is the spalling fracture energy of FRP sheet-concrete interface under dowel force $(\mathrm{N} / \mathrm{mm})$.

By combining Equations 12 and 13, it can be known that the dowel force capacity can be predicted if the interface spalling fracture energy $\mathrm{G}_{\mathrm{fs}}$ is calibrated. Figure 21 and Figure 22 show, respectively, the relationship between the interface spalling energy $G_{f s}$ and the peeling angle $\theta$, and the relationship between the dowel force $P_{d}$ and interface spalling energy $G_{f s}$. The comparison between the experimental and analytical results shows that the interface debonding failure under dowel force (Equations 12 and 13) can be modeled. It is also found through experiments that the interface spalling fracture energy increases with concrete strength, but decreases with increasing the stiffness of FRP and adhesive elastic modulus. Increasing the FRP stiffness results in a smaller peeling angle (see Figure21), and, consequently, can help decrease the dowel deformation. However, the smaller peeling angle brought by the higher FRP stiffness 
means that the dowel deformation of FRP sheets should be more strictly limited when using an FRP with high stiffness, if the FRP sheets need to achieve a high tensile stress.

\subsection{Spalling Prevention Design of Concrete Structure by Using FRP Sheets}

FRP sheets are increasingly being used to prevent spalling of concrete blocks from deteriorated tunnel linings or elevated bridges. Guidelines for anti-spalling design of concrete structures by using FRP sheets can be based on the bond modeling of the FRP sheet-concrete interface under dowel force. In practic, interface peeling caused by the spalling force $P_{\text {spalling }}$ of deteriorated concrete blocks may propagate in two dimensions, as shown in Figure 23. Punching shear test results for concrete slabs retrofitted with bidirectional FRP sheets, in which the tension stiffness in $\mathrm{x}$ and $\mathrm{y}$ directions are equal, showed that the shape of peeled interface under the action of the spalling force is nearly square. Moreover, the interface peeling angle $\theta$ (Fig.23) was found to be constant during interface debonding process. Based on these two observations, the relationship between the spalling force and the peeling angle can be obtained through integration as follows [41]:

$$
\frac{P_{\text {spalling }}{ }^{x(y)}}{2\left(r+L_{p}\right)}=2 E_{x(y)} t_{x(y)}\left(\frac{1}{\cos \theta}-1\right) \sin \theta
$$

where $\mathrm{P}_{\text {spalling }}{ }^{\chi^{*}(y)}$ is the interface spalling resistance contributed by the tension stiffness in $\mathrm{x}$ or $\mathrm{y}$ direction; $E_{x(y)} t_{x(y)}$ is the tension stiffness of FRP in $x$ or $y$ direction; $r$ is the radius of concrete column used for imposing spalling force; $\mathrm{L}_{\mathrm{p}}$ is the largest peeled length along $\mathrm{x}$ direction; and $\theta$ is the interface peeling angle as shown in Figure 23.

It can be seen from Figure 23 that $2\left(\mathrm{r}+\mathrm{L}_{\mathrm{p}}\right)$ is the maximum width of the peeled FRP sheets in the $\mathrm{x}$ or $\mathrm{y}$ direction. By comparing Equation 12 and Equation 14, it can be concluded that the spalling forces per unit width of FRP sheets can bear in unidirectional and bidirectional strengthening cases are the same if the FRP sheets have same tension stiffness. In spalling prevention design with bidirectional or multidirectional waved FRP sheets, the sum of FRP tension stiffness in two crossed directions can be taken as a design parameter. The bond characteristic parameter of the FRP sheet-concrete interfaces under dowel failure, like the critical peeling angle $\theta$ or the interface spalling fracture energy $\mathrm{G}_{\mathrm{fs}}$ can be calibrated through the simple inidirectional dowel test, as shown in Fig.11. Wu et al. proposed a value of $0.5 \mathrm{~N} / \mathrm{mm}$ for $\mathrm{G}_{\mathrm{fs}}$, based on their shear punching test results [41]. It can be seen in Figure 23 that the 
proposed value can give a conservative prediction.

In practice, FRP sheets used to prevent the tunnel linings from spalling, Kojima et al. proposed the following design guideline by using a parameter called the interface spalling strength $\mathrm{s}_{\mathrm{p} 0}$, which is defined as the interface spalling force divided by the peeled circumference of the interface under that force [42].

$$
\begin{aligned}
& \gamma_{i} \frac{W_{d}}{P_{\text {spalling }}} \leq 1.0 \\
& P_{\text {spalling }}=2 \cdot S_{p 0} / \gamma_{m} \cdot\left(l_{t}+\gamma_{a} \cdot l_{a}\right) / \gamma_{b}
\end{aligned}
$$

where $\mathrm{W}_{\mathrm{d}}$ is supposed spalling driving force in design, $\mathrm{P}_{\text {spalling }}$ is the spalling resistance for design, $\gamma_{i}$ is the safety factor for structures, $S_{p 0}$ is the interface spalling strength, $\gamma_{a}$ is the reduction factor by the curvature of tunnel linings, and $l_{a}$ and $l_{t}$ are the dimensions of possible spalling blocks in the longitudinal and transverse dimension of tunnel respectively.

In addition, when FRP sheets with a specific tension stiffness is provided for design, the strength capacity of FRP sheets should be checked by Equations 17 and 18 to prevent sheet rupture.

$$
\begin{aligned}
& \gamma_{m} \frac{\sigma_{f}}{f_{t}} \leq 1 \\
& \sigma_{f}=E_{f} \varepsilon_{f}=E_{f}\left(\frac{1}{\cos \theta}-1\right)
\end{aligned}
$$

where $\sigma_{f}$ is the stress in the FRP sheets when the interface peeling happens, $f_{t}$ is the tensile strength of FRP sheets, $E_{\mathrm{f}}$ is the elastic modulus of the FRP sheets, $\gamma_{m}$ is the safety factor for the tensile strength of FRP sheets, and $\theta$ is the critical peeling angle.

It can be seen from Equations 15 to 18 that two interface parameters are needed for design. One is the peeling angle $\theta$ and the other is the interface spalling strength $\mathrm{s}_{\mathrm{p}}$. Based on the bond modeling presented above, with a given spalling energy, $\mathrm{G}_{\mathrm{fs}}, \theta$ can be determined based on Equation 12 and $\mathrm{s}_{\mathrm{p} 0}$ can obtained according to its definition and Equation 14 as follows:

$$
s_{p o}=\frac{P_{\text {spalling }}}{4 \sqrt{2}\left(r+L_{p}\right)}=\frac{1}{\sqrt{2}} E_{f} t_{f}{ }^{x+y}\left(\frac{1}{\cos \theta}-1\right) \sin \theta
$$

where $\mathrm{E}_{\mathrm{f}} \mathrm{t}_{\mathrm{f}}^{\mathrm{x}+\mathrm{y}}$ is the sum up of the tension stiffness of FRP sheets in crossed directions, and, from Figure 23 
that $4 \sqrt{2}\left(r+L_{p}\right)$ is the circumference of peeled interface.

Therefore, for the spalling prevention design of concrete structures using FRP sheets, the interface spalling fracture energy $\mathrm{G}_{\mathrm{fs}}$ is the only needed bonding characteristic parameter of FRP sheet-concrete interface and it can be calibrated from a simple unidirectional dowel test, as discussed above.

\section{MEBER BEHAVIOR AND BOND PROPERTY}

\subsection{Numerical Simulation}

Failures of FRP sheet strengthened concrete members are usually related to the debonding of FRP sheets from concrete substrates. Consequently, the improvement in predicting the strength, stiffness, and ductility behaviors of FRP sheet strengthened concrete members depends upon using interface bond models within appropriate numerical analytical tools. That is also the prerequisite of achieving optimum retrofitting design based on desirable performances. Owing to the special localized delamination and slip phenomena of the FRP composite-concrete interface, it is difficult to use conventional design theory like the fiber modeling, which is generally used in beam or column analysis, to evaluate the FRP strengthened RC members precisely. To consider the highly nonlinear interface delamination and slip behavior together with the various types in cracking behaviors, the FEM may be a more useful approach.

FEM analytical method with a smeared crack model has been used by many researchers [57-60] mainly for analyzing the performance of FRP externally strengthened RC beams. Although they can show acceptable agreement between their experimental and analytical results, their proposed interface bond models showed significant differences with those observed in pull-out bond tests, and, hence, a lack of common applicability. It has been recognized that the smeared crack approach is limited in the ability to represent the stress intensity at the delamination tip of FRP laminate strengthened RC beams [61]. For this reason, a fracture energy-based criterion is a more suitable solution to describe the bi-material elasticity and the complex stress intensity at the delamination tip governing the propagation of delamination.

Wu and Niu performed two-dimensional FEM analysis (with the ABAQUS Program) based on discrete crack method to clarify the debonding initiation from the mid-span flexural cracks. In their analysis, they applied energy-based bilinear interfacial $\tau \sim S$ relationship, which was obtained from the pull out bond test, in their analysis [62-63]. Kishi et al. performed three-dimensional FEM analysis (with the DIANA 
Program) on FRP sheet strengthened RC beams. They proposed a mix-mode interfacial model, in which both the interfacial tension and shear model are assumed as cut-off type, without consideration of the tension and shear softening [64]. For both two-dimensional and three-dimensional FEM analysis based on discrete method, spacing and localizations of cracks need to be defined by introducing crack elements.

The premature interface debonding in FRP strengthened concrete structures is a localized phenomenon and highly depends on the cracking behavior of concrete. Therefore, improvements on both interface bond models and the advanced discrete methods are necessary. In the authors' laboratory, a discrete crack approach based on rigid body spring method (RBSM) has been developed [65-66]. The most attractive feature is its ability to simulate the random fracture or cracking process of concrete materials. RBSM, with the fracture-energy-based nonlinear bond model developed by the authors, was applied to simulate tension stiffness behavior of a concrete prism reinforced with a reinforcing bar at its center and externally bonded carbon FRP sheets on two sides (see Figure 24), which was experimentally investigated in a previous study [67]. The simulated results show a good agreement with the experimental ones in average tensile strains in the concrete, steel bar and FRP sheet and bond stresses of the steel bar and FRP sheet. This numerical scheme with RBSM could also analyze a reinforced concrete beam strengthened with FRP sheet in flexure [66]. Using fracture-energy-based nonlinear bond models, which have been well verified in bond element level, the analytical tool is expected to clarify the different interfacial debonding behaviors in a unified way.

\subsection{Optimal Interface Bond Property for Member Behaviors [21]}

Good understanding on the bond properties and bond modeling of FRP sheet-concrete interface can help not only to improve the predictions of the load carrying capacity and deformation behavior of FRP strengthened concrete members, but also to find appropriate interface bonding materials, which can offer suitable interface bond characteristics to optimize the performances of strengthened RC members. In addition, it is well known that FRP strengthening materials have tensile strength. However, this high strength can seldom be fully utilized in practice owing to the premature debonding. Besides the traditional prestressing and mechanical anchorage systems (for example U-shape wrapping and mechanical bolts) at the ends of FRP sheets, some other novel bonding technologies, such as near surface mounting (NSM) and other mechanical fastening for the bond interface as a substitute of adhesive bonding in FRP flexurally strengthened RC members have been developed based on different strengthening FRP materials 
[68-70]. However, interface bond properties of FRP strengthened reinforced concrete structures using these novel technologies need to be studies quantitatively such that the interface bond materials can be optimally selected, leading to optimized use of the FRP materials.

The predominant local bond characteristic of an FRP sheet-concrete interface is the interfacial fracture energy $G_{f}$. Numerical analysis has shown that improvement of interfacial fracture energy may not be necessary for a ductility-orientated member, except when the member is poorly reinforced but strengthened with high stiffness FRP sheets [70]. Instead, the improvement of the fracture energy of FRP material itself becomes more important. However, the interface fracture energy significantly affects the performances of RC beams strengthened with FRP sheets in flexure and shear. In Japan, design procedure based on verifying the fracture energy to calculate the flexural capacity of FRP sheet strengthened RC beams has been adapted in the design recommendation of JSCE [20].

Figure 25 shows an example of analytical results on the flexural capacity of strengthened RC beams by using the interfacial fracture energy [71]. The material parameters used in calculation are shown in Table 2. It can be seen in Fig. 25 that if the fracture energy is increased, the flexural capacity also increases, but will stop increasing if compression failure of concrete occurs. The typical value for the fracture energy of FRP sheet-concrete interface is about equal to $1.2 \mathrm{~N} / \mathrm{mm}$ [30], which means that the flexural capacity of a retrofitted $\mathrm{RC}$ member can be further improved if the fracture energy can exceed $1.2 \mathrm{~N} / \mathrm{mm}$. But on the other hand, it can be seen from Fig. 25 that the flexural capacity will not increase efficiently if the fracture energy exceeds $2.0 \mathrm{~N} / \mathrm{mm}$. So any value of the interfacial fracture energy, which is less than $2.0 \mathrm{~N} / \mathrm{mm}$, for flexural strengthening is optimum, because the flexural capacity is controlled directly by the interfacial fracture energy. The maximum flexural capacity can be achieved when the fracture energy is 2.0 N/mm. The desired fracture energy can be obtained most effectively by selecting an adhesive resin having either an appropriate stiffness or an appropriate thickness.

For shear strengthening case, a similar analysis can be performed. To predict the ultimate shear capacity of FRP strengthened member, Kamiharako et al. developed a rigid body model with a single shear crack as shown in Fig.26 based on the following assumptions [73]:

- the angle $\theta$ between the longitudinal axis of the member and the shear crack is $35^{\circ}$;

- deformation of the member after shear cracking is represented by rotation of the member;

- delamination of the sheets bridging a major diagonal crack is described by using a constitutive 
model of the bond between the sheet and the concrete (see Figure 19);

- concrete blocks on either side of a main shear crack are rigid, and the FRP sheets are elastic;

- the strain of concrete at compressive zone is defined as function of the angle $\rho$ shown in Fig.26.

The analysis can consider the effects of local interfacial bond stress-slip behavior, while the shear forces carried by FRP sheets are evaluated by considering the delamination process of the sheet in each element along the retrofitted member for an increasing angle $\rho$ (see Fig. 26). This analytical method can judge whether the failure mode is shear compression failure or sheet rupture. The ultimate shear capacity of retrofitted member, $V_{f y}$, is calculated as follows:

$$
V_{f y}=V_{c}+V_{s}+V_{f}
$$

where $V_{c}$ is the shear force carried by the concrete, $V_{s}$ is the shear force carried by the web reinforcement, and $V_{f}$ is the shear force carried by the sheet. The shear forces, $V_{c}$, and $V_{f}$ are calculated based on conventional truss models.

Based on this rigid body model, the sensitivity of the interface fracture energy $\mathrm{G}_{\mathrm{f}}$ on the shear capacity of FRP sheet strengthened RC members was analyzed by using a cut-off bond model as shown in Figure 27 [74], the material parameters used in parameters are shown in Table 3. Figure 28 shows the relationship between the fracture energy and the shear capacity of strengthened members in the cases where different stiffness of FRP (thickness $t_{f}$ ) is used. It can be seen that when the thickness of FRP sheets $t_{f}$ lies between 0.05 and $0.15 \mathrm{~mm}$, the shear capacity decreases with the increase of interfacial fracture energy, because the sheet is ruptured before the interface delaminating in the analysis. However, when the thickness of FRP sheets $t_{f}$ exceeded $0.3 \mathrm{~mm}$, the shear capacity can be improved with the increase of fracture energy. Though the analysis is qualitative, the following conclusion can be drawn, based upon the analytical results. When the thickness (stiffness) of the FRP sheets is very small, the fracture energy is not so important; whereas when the thickness (stiffness) increases, the improvement in the interface fracture energy can improve the significantly shear capacity of strengthened members.

Our study of the literature persuades us that there are still great gaps in understanding the contribution of interface bond properties to FRP strengthening for a wide range of cases. Engineers and manufacturers lack both experience and adequate data to choose the best materials in many strengthening cases. Even though the new FRP strengthening techniques we are championing are costly now, we are interested in further work to optimize these new techniques for a given structural performance and cost-effectiveness. 
Improved knowledge of the interface bond is needed to understand the composite action of the FRP strengthening materials and concretes structures. While it is encouraging for engineers to see emergence of new FRP strengthening techniques, it is paramount to understand the composite action between the FRP and the concrete structure so that the design of the strengthening can be based on performance-based provisions.

\section{CONCLUDING REMARKS}

Over the last decase, Design guidelines for upgrading concrete structures with FRP sheets have been developed based on fundamentals and have now reached a stage where refined design is possible. More attentions need to be paid to the issues of optimal selection of strengthening materials, interface bonding materials, as well as how to utilize efficiently the advantages of FRP materials related to desirable structural behavior. Solutions to these issues depend on improved techniques to predict the the performance of concrete structures after upgrading, in which the focus needs to be advanced modeling of the bond at the FRP sheet-concrete interfaces at the micro or element level and also at the member level. This paper has summarized the existing test methods for evaluating bond behavior of FRP sheet-concrete interfaces and introduced some updated modeling methods for the bond properties of FRP sheet-concrete interfaces under various conditions, as well as the applications of some of those models in FRP strengthening examples. The authors have introduced some of the latest achievements related to the interface bond, which are included in the report of JCI Technical Committee on Retrofit Technology, on which the first author served [21]. It is the authors' hope that the descriptions in this paper on modeling the interface bond at the micro-level, the modeling of FRP strengthened members with respect to local bond properties, and the role of the interface bond properties on member behavior will be informative to researchers, engineers, and material manufacturers and enable them to advance their understanding of FRP retrofitting technology. 


\section{REFERENCES}

1. Karbhari V. M.: Material Considerations in FRP Rehabilitation of Concrete Structures, Journal of Materials in Civil Engineering, ASCE, Vol.13, No.2, 90-97, 2001

2. Kaiser H., and Karbhari V. M. : Quality and Monitoring of Structural Rehabilitation Measures, Part I: Description of Potential Defects, Report Submitted to the Oregon Department of Transportation under Contact Number 18347, Version 1.2, UCSD, 2001

3. Ueda T., and Sato Y. : New Approach for Usage of Continuous Fiber as Non-Metallic Reinforcement of Concrete, Structural Engineering International, 2. 111-116, 2002

4. Lihoshi C., Fukuyama H., Matsumoto Y., and Abe S. : Strengthening Effects of Reinforced Concrete Elements with Polyacetal Fiber Sheets, ACI SP 188-58, 559-669

5. Maruyama K., Shimomura T., Shinbo T., Nakai Y.: Ductility Improvement Mechanism of Columns by Wrapping of FRP Sheets, Advances in Structures, Hancock et al. (eds), Swets \& Zeitlinger, Lisse, 2003

6. Buyukozturk O., and Hearing B.: Fracture Behavior of Precracked Concrete Beams Retrofitting with FRP, Journal of Composites for Construction, ASCE, Vol.2, No.3, 138-144, 1998

7. Sebastian W. M.: Significance of Midspan Debonding Failure in FRP-Plated Concrete Beams, Journal of Structural Engineering, ASCE, Vol.127, No.7, July, 2001

8. Triantafillou T. C.: Guidelines for the Dimensioning of Reinforced Concrete Elements Strengthened with Sika Carbondur/Sikawrap, University of Patras, Greece, April, 1999

9. Externally Bonded FRP Reinforcement for RC Structures, fib bulletin 14 TC Report, 2001

10. Maalej M., and Bian Y.: Interfacial Shear Stress Concentration in FRP-Strengthened Beams, Composite Structures, 54, 417-426, 2001

11. Nguyen D. M., Chan T. K., and Cheong H. K.: Brittle Failure and Bond Development Length of CFRP-Concrete Beams, Journal of Composites for Construction, ASCE, Vol.5, No.1, 12-17, 2001

12. Jone R., Swamy R. N., and Charif A. : Plate Separation and Anchorage of Reinforced Concrete Beams Strengthened by Epoxy-Bonded Steel Plates, The Structural Engineer, Vol. 66, No.5, $85-94,1988$

13. Robert T. M., and Haji-Kazami H. : A Theoretical Study of the Behaviors of Reinforced 
Concrete Beams Strengthened by Externally Bonded Steel Plates, Proceedings of the Institution of Civil Engineers, Part II, Vol. 87, 39-55, 1989

14. Etman E. E., and Beeby A.W. : Experimental Program and Analytical Study of Bond Stress Distribution on a Composite Plate Bonded to a Reinforced Concrete Beam, Cement and Concrete Composites, 22. 281-291, 2000

15. Lau K. T., Dutta P. K., Zhou L. M. and Hui D.: Mechanics of Bonds in an FRP Bonded Concrete Beam, Composites, Part B: engineering, 32, 491-502, 2001

16. Smith S. T., and Teng J. G.: FRP-strengthened RC beams. I: Review of debonding strength models, Engineering Structures, Vol.24, No.4, 385-395, 2002

17. Smith S. T., and Teng J. G.: FRP-strengthened RC beams, II: Assessment of debonding strength models, Engineering Structures, Vol.24, No.4, 397-417, 2002

18. Mukhopadhyaya P., and Swamy R. N.: Interface Shear Stress: A New Design Criterion for Plate Debonding, Journal of Composites for Construction, Vol.5, No.1, 35-43, Feb. 2001

19. EI-Mihilmy M.T., and Tedesco J. W.: Prediction of anchorage failure for reinforced concrete beams strengthened with fiber polymer plates, ACI Structural Journal, v.98, No.3, 301-313, May-June 2001

20. Recommendations for Upgrading of Concrete Structures with Use of Continuous Fiber Sheets, JSCE, Concrete Library, 2000, 7

21. International Symposium on Latest Achievement of Technology and Research on Retrofitting Concrete Structures, Proceedings and Technical Report on JCI Technical Committee, July 14-15, 2003, Kyoto

22. Sato, Y., Kimura, K., and Kobatake, Y.: Bond Behaviors between CFRP Sheet and Concrete.”, Journal of Structural Construction Engineering, AIJ, No.500, 75-82, 1997 (in Japanese)

23. Bizindavyi, L. and Neale, K. W.: Transfer Length and Bond Strength for Composites Bonded to Concrete, Journal of Composites for Construction, ASCE, 3(4), 153-160, 1999

24. Ueda, T., Sato, Y., and Asano, Y.: Experimental Study on Bond strength of Continuous Carbon Fiber Sheet.” ACI, SP 188-37, 407-413, 1999

25. Lorenzis, L. De., Miller, B., and Nanni, A.: Bond of Fiber-Reinforced Polymer Laminates to Concrete, ACI Material Journal, 98(3), 256-264, 2001 
26. Nakaba, K., Kanakubo, T., Furuta, T., and Yoshizawa, H.: Bond Behavior between Fiber-Reinforced Polymer Laminates and Concrete, ACI Structural Journal, 98(3), 359-167. 2001

27. Brosens, K. and Gemert, D. Van.: Anchorage Stresses between Concrete and Carbon Fiber Reinforced Laminates, Non-Metallic (FRP) Reinforcement for Concrete Structures, Proceedings of Third International Symposium, Vol.1, 271-278, 1997

28. Brosens, K. and Gemert, D. Van.: Anchorage Design for Externally Bonded Carbon Fiber Reinforced Polymer Laminates, ACI, SP 188-56, 635-641, 1999

29. Sato, Y., Asano, Y., and Ueda, T. : Fundamental Study on Bond Mechanism of Carbon Fiber Sheet, Concrete Library International, JSCE, No.37, June 2001, 97-115, 2000

30. Yoshizawa, H., Wu, Z., Yuan, H., and Kanakubo, T.: Study on FRP-Concrete Interface Bond Performance, Transactions of JSCE, No.662/V-49, 105-119, 2000

31. Chajes, M. J., Finch, William. W., Januszka, T. F. and Thomson, T. A.: Bond and Force Transfer of Composite Material Plates Bonded to concrete, ACI Structural Journal, 93(2), 208-217, 1996

32. Horiguchi, T. (1997). "Effect of Test Methods and Quality of Concrete on bond strength of CFRP Sheet." Non-Metallic (FRP) Reinforcement for Concrete Structures, Proceedings of Third International Symposium, Vol.1, 265-270.

33. Mitsui, M., Fukuzawa, K., Numao, T. and Fuda, I: Relations between Surface Roughness Indexes and Bond strength between CFRP sheets and Concrete, Journal of Society Material Science. Japan, 49(6), 685-691, 2000 (In Japanese)

34. Dai J. G., Sato Y., and Ueda, T.: Improving the Load Transfer and Effective Bond Length for FRP Composites Bonded to Concrete, Proceedings of the Japan Concrete Institute, Vol.24, 1423-1428, 2002

35. Nishida, H., Simomura, T., Kamiharako, A., and Maruyama, K.: Bond Behaviors between the FRP Sheets and concrete, Proceedings of JCI, 21(3), 1507-1511, 1999 (in Japanese).

36. Xu Y. W., Qiao P. Z., and Davalos J. F.: Exploratory Evaluation of Mode-I Fracture Toughness of Concrete-Composite Bonded Interfaces, 15th ASCE Engineering Mechanics Conference, New York, 2002

37. Mitsui M., Fukuzawa K., and Numao T.: Influence of temperature on cleavage bonding 
properties between CFRP sheets and concrete, ICCI-02, June, in CD-ROM, 2002.

38. Dai J. G., Sato. Y., Ueda T., and Muttaqin H. : Mode I Fracture Behaviors of FRP-Concrete Interfaces, Proceedings of the Japan Concrete Institute, Vol. 25, 1577-1582, 2003

39. Boyajian D., Davalos J. F., Ray I., and Qiao P. Z.: Evaluation of interface fracture of concrete externally reinforced with FRP, $2^{\text {nd }}$ International Conference of Durability of FRP Composites for Constructions, Montreal, Canada, 2002

40. Karbhari V. M., and Engineer M.: Investigation of Bond between Concrete and Composites: Use of a Peeling Test, Journal of Reinforced Plastics and Composites, Vol.15, 208-227, 1996

41. Wu Z. S., Asakura T., Yoshizawa H., Yuan H., Kobayashi A., and Takahashi T: Experimental and analytical studies on peeling behaviors and spalling resistance effect of externally bonded continuous fiber sheets. Proceedings of Japan Society of Civil Engineering, Vol. 49, No. 662, $45-58,2000$.

42. Kojima Y., Yoshizawa K., Muguruma T., Kobayashi A., Wakana K., Asakura T., and Wu Z. S.:, A Design Method of Fiber Reinforced Plastic Methods as a Countermeasure for Concrete Spalling from Tunnel Lining, Proceeding of JSCE, No. 746/VI-62, 101-116, 2004 (in Japanese)

43. Dai J. G., Ueda T., Sato Y., and Jaqin H. : Dowel resistances of bond interfaces between FRP sheets and concrete(submitted), CICE 2004, Australia

44. Swamy R. N. : Debonding of Carbon Fiber Reinforced Polymer Plate from Concrete Beams, Proc. Ins. Civ. Engrs Structs \& Bldgs, 134, 301-317, Nov., 1999

45. Rahimi H., and Hutchinson A.: Concrete Beams Strengthened with Externally Bonded FRP Plates, Journal of Composites for Construction, ASCE, Vol. 5, No. 1, 44-56, 2001

46. Ozaki H., Ueda T. and Dai J.G, Effects of the Concrete Cover Thickness and Shear Reinforcements on the Behaviors of FRP Sheet Strengthened RC Beams, JSCE Annual Conference, Tokushima, 2003 (in Japanese)

47. Dai J. G., Ueda T., Sato Y., and Ozaki H. : Experimental Study on Mix-Mode Fracture of FRP Sheet-Concrete Interfaces, Proceedings of JCI International Symposium: Latest Achievement in Technology and Research on Retrofitting Concrete Structures, July, 2003, Kyoto, 113-120.

48. Santos, A. C. Dos., Bittencourt T. N., and Gettu, R. : Experimental Analysis of Interface between CFRP and Concrete using Cylindrical Specimens, Proceedings of FRPRCS-6, Edited by 
K.H Tan, Singapore, 8-10, July, 183-182, 2003

49. Dai J. G.,, Ueda T., and Sato Y.: Development of Nonlinear Bond Stress Slip Model with a Simple Method, Submitted to Journal of Composite for Construction (accepted for publication), ASCE, 2004

50. Neubauer, U., and Rostásy, F. S.: Design Aspects of Concrete Structures Strengthened with Externally Bonded CFRP plates, Proceedings of $7^{\text {th }}$ International Conference on Structural Faults and Repairs, ECS Publications, Edinburg, Scotland, Vol. 2, 109-118, 1997

51. Chen J. F., and Teng J.G.: Anchorage Strength Models for FRP and Steel Plates Bonded to Concrete, Journal of Structural Engineering, Vol. 127, No.7, 784-791, 2001

52. Yuan, H., Wu, Z., and Yoshizawa, H. : Theoretical Solutions on Interfacial Stress Transfer of Externally Bonded Steel/Composite Plates, J. Structural. Mech. Earthquake Eng. JSCE, 18(1), $27-39,2001$

53. Kanakubo, T., Furuta, T., and Fukuyama, H., Bond Strength between Fiber-Reinforced Polymer Laminates and Concrete, Proceedings of FRPRCS-6, Edited by K.H Tan, Singapore, 8-10, July, 2003, 134-143, 2003

54. Dai J. G. : Interfacial Models for Fiber Reinforced Polymer (FRP) Sheets Externally Bonded to Concrete, Ph. D dissertation, Hokkaido University, Japan, 2003

55. Täljsten B.: Defining anchor lengths of steel and CFRP plates bonded to concrete, International Journal of Adhesion and Adhesives, 17(4), 319-327, 1997

56. Gabriel Sirbu, Model for Shear Resisting Capacity of Reinforced Concrete Columns Strengthened with Carbon Fiber Sheets, Doctoral dissertation, Hokkaido University, 2000

57. Liu Y. Q., Hikosaka L., Kameyama Y., and Harada T.: FEM Analysis on the Failure Behaviors of FRP strengthened RC Beams, Proceedings of JCI, Vol. 20, No.3, 1-6, 1998 (in Japanese)

58. Lee H. C., Tomozawa F., Noguchi T., and Shikanoke T.: FEM Analysis on the FRP Flexurally strengthened RC Beams, Proceedings of JCI, Vol. 18, No.1, 1065-1070, 1996 (in Japanese)

59. Arduini M., Tommaso A.D., and Nanni A.: Brittle Failure in FRP Plate and Sheet Bonded Beams, ACI Structural Journal, Vol. 94, No. 4, 363-370, July-Aug., 1997

60. Rahimi H., and Hutchinson A.: Concrete Beams Strengthened with Externally Bonded FRP Plates, Journal of Composites for Construction, Vol. 5, No. 1, 44-56, Feb., 2001 
61. Phillip H. B.: Delamination in Reinforced Concrete Retrofitted with Fiber Reinforced Plastics, Doctoral Dissertation, MIT, 2000

62. Wu Z., and Niu H.: Study on Debonding Failure Load of RC Beam Strengthened with FRP sheets, Journal of Structural Engineering, JSCE, Vol.46A, 1431-1441, 2000

63. Niu H., and Wu Z. : Interfacial Debonding Mechanisms Influenced by Flexural Cracks in FRP-strengthened Beams, Journal of Structural Engineering, JSCE, Vol. 47A 1277-1288, 2000

64. Kishi N., Mikami H., and Zhang G. F. : Numerical Analysis of Debonding Behavior of FRP Sheet for Flexural Strengthening RC Beams, Proceedings of JSCE, No.725, V.58, 255-272, 2003(in Japanese)

65. Nagai K., Sato Y., and Ueda T., Numerical Simulation of Fracture Process of Plain Concrete by Rigid Body Spring Method, Proceeding of the first fib congress, 99-106, Osaka, 2002

66. Yito T. : Study on Fracture Characteristics of CFRP Sheet Reinforced RC Member with Soft Bond Layer, Master thesis, Hokkaido University, 2003

67. Ueda T, Yamaguchi R, Shoji K and Sato Y, Study on behavior in tension of reinforced concrete members strengthened by carbon fiber sheets, Journal of Composites for Construction, ASCE, Vol.6, No. 3, pp.168-174, 2002

68. Rizkalla S., and Haasan T. : Various FRP Strengthening Techniques for Retrofitting Concrete Structures, FRP Composites in Civil Engineering, Vol. $\alpha$, pp.1033-1040, Dec.2001

69. Carolin A., Nordin S. H., and Taljsten B. : Concrete Beams Strengthened with Near Surafce Mounted Reinforcement of CFRP, FRP Composites in Civil Engineering, Vol. $\alpha$, pp.1059-1066, Dec. 2001

70. Lamanna A. J.: Flexural Strengthening of Reinforced Concrete Beams with Mechanically Fastened Fiber Reinforced Polymer Strips, Doctoral dissertation, University of Wisconsin-Madison, 2002

71. Sato, Y. and Vecchio, F. J. Tension Stiffening and Crack Formation in Reinforced Concrete Members with Fiber-Reinforced Polymer Sheets," Journal of Structural Engineering, ASCE, Vol.129, Issue 6, pp.717-724, June 2003.

72. Yokota, M., Shimomura, T., Kamiharako, A., Maruyama K. : Influence on Mechanical Property of Retrofitted Member with Continuous Fiber Sheet, Proceedings of the Japan Concrete Institute, 
Vol.24, No.2, pp.1399-1404, 2002. (in Japanese)

73. Kamiharako A., Shimomura T., Maruyama K. : Evaluation Method for Shear Capacity of RC Members Retrofitted with Externally Bonded Continuous Fiber Sheet, JSCE, Concrete Library International, No. 37, pp.147-160, 2001.

74. Shinbo, T., Shimomuta, T., Maruyama, K., and Kamiharako, A. : Sensitivity Analysis on Shear Capacity of Continuous Fiber Reinforced Concrete, Proceedings of the Japan Concrete Institute, Vol.22, No.3, pp.313-318, 2000. (In Japanese) 
Figures

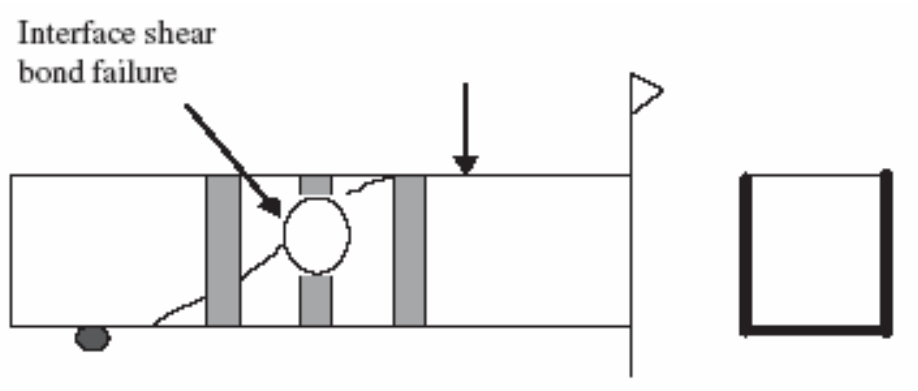

Figure 1 Interface debonding failure: shear strengthening cases

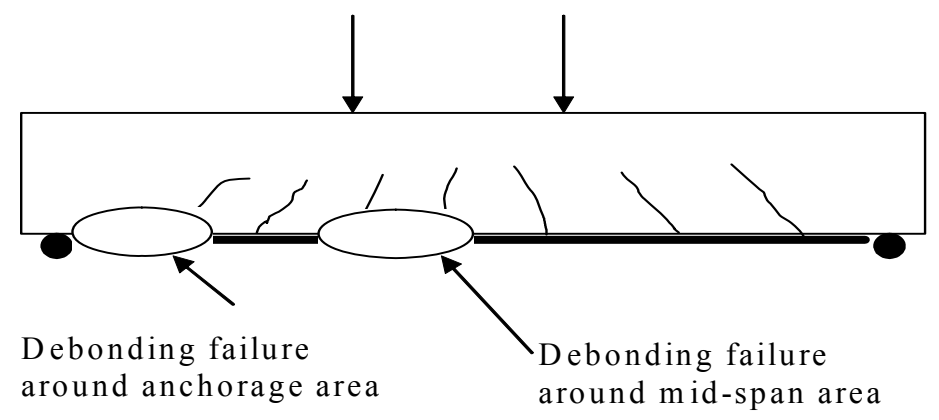

Figure 2 Interface debonding failure: flexural strengthening cases

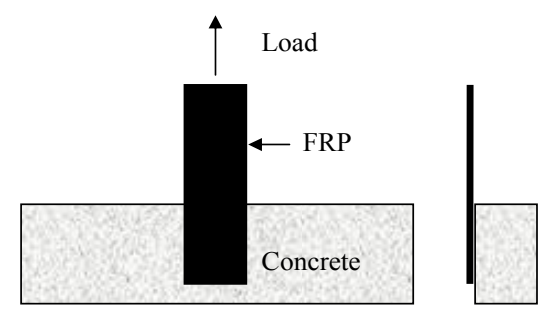

Figure 3 single-lap shear bond test 


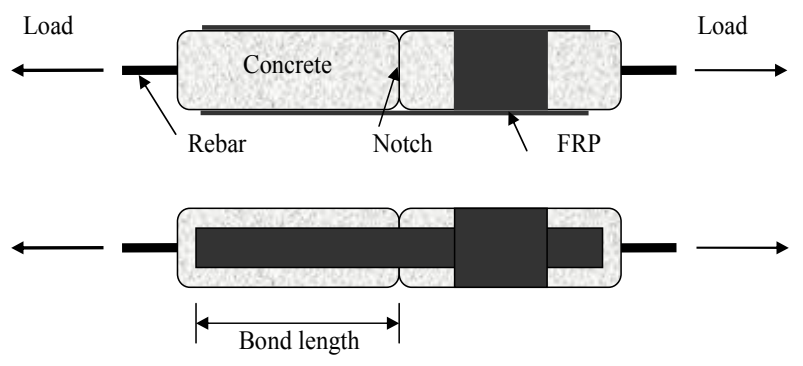

Figure 4 double-lap shear bond test

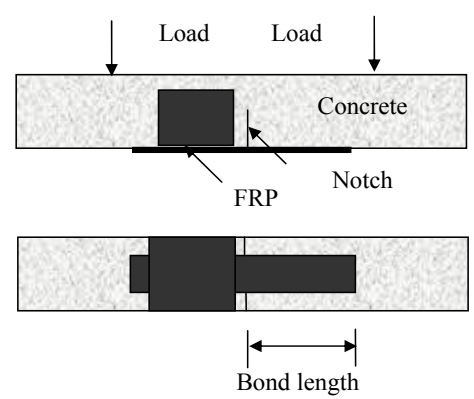

Figure 5 bending-type shear bond test

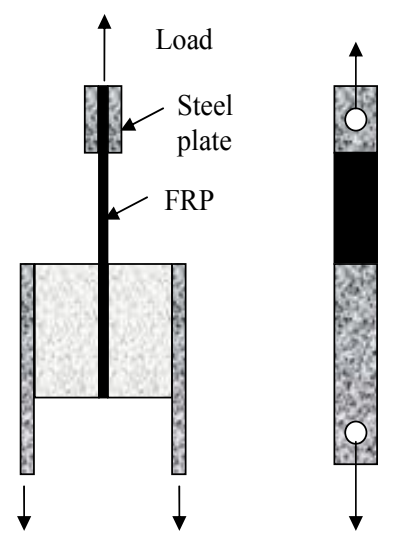

Figure 6 inserted type shear bond test 


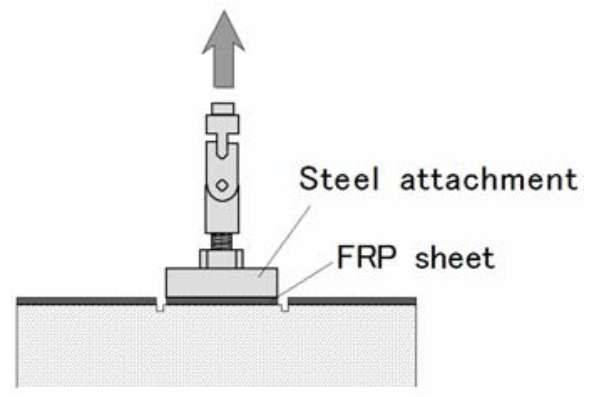

Figure 7 direct tension test

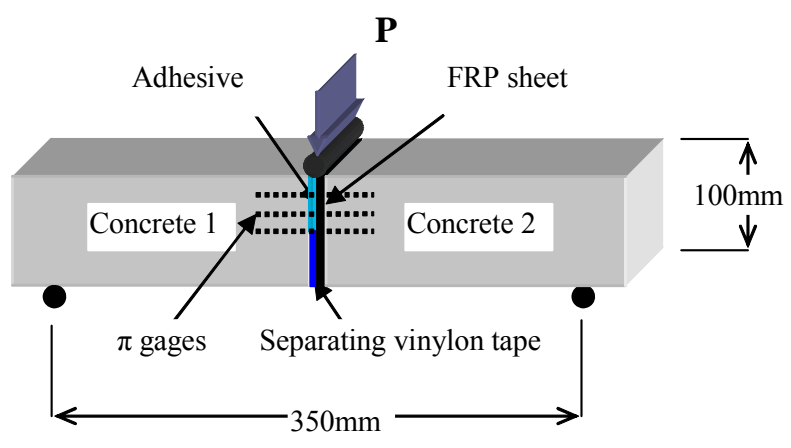

Figure 8 three-point bending test

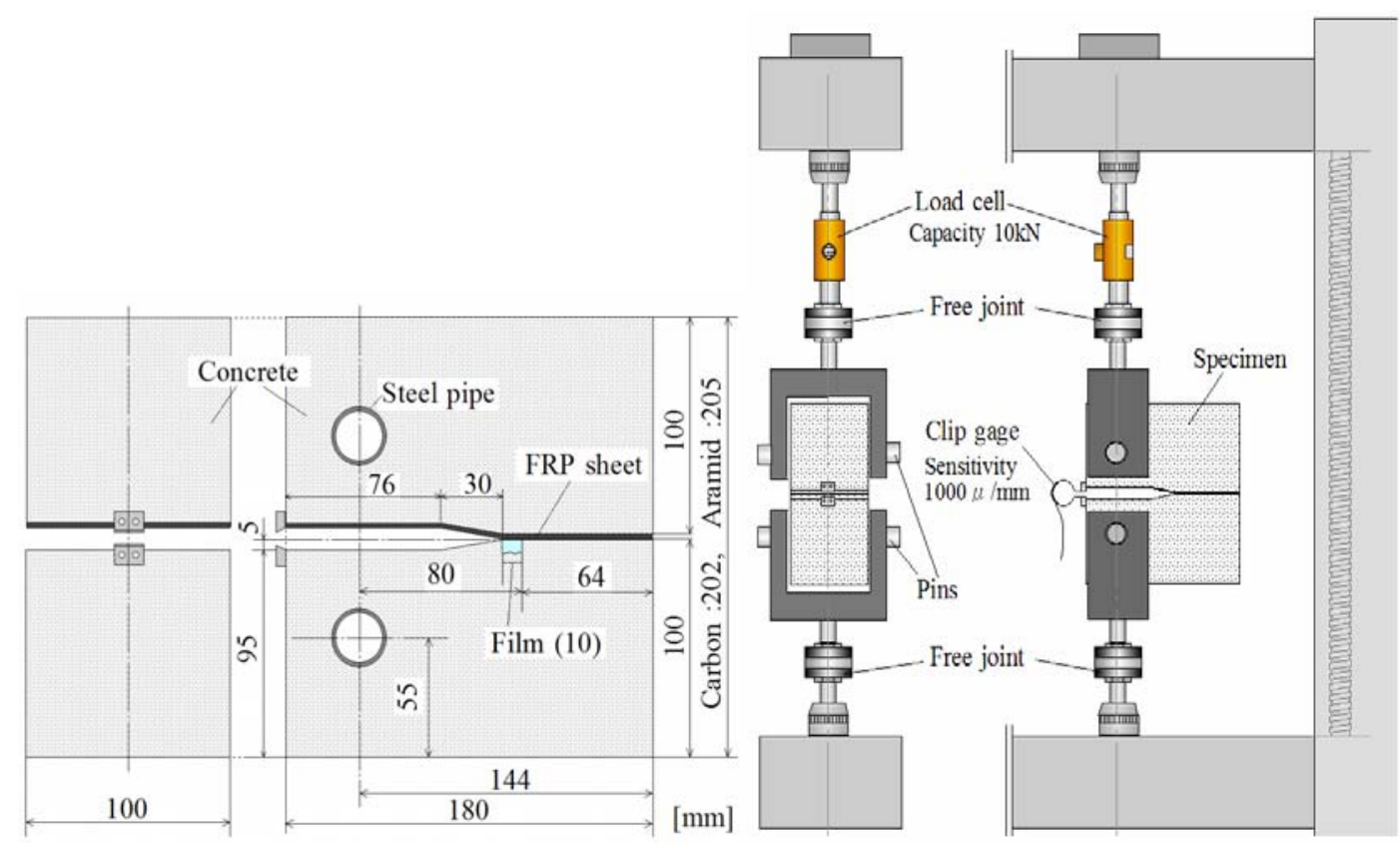

Figure 9 wedging splitting test 
Concrete blocks

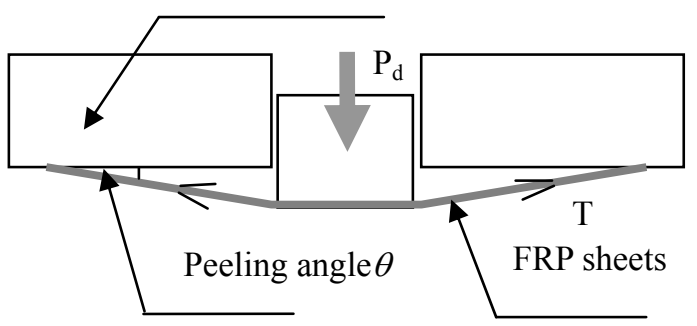

Figure 10 Dowel test for FRP sheet-concrete interfaces

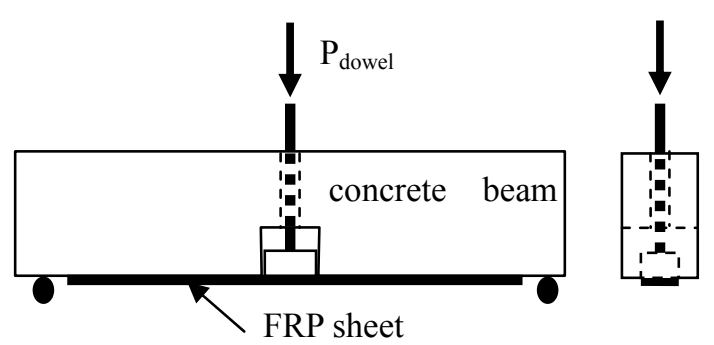

Figure 11 beam-type (one-directional sheet) dowel test

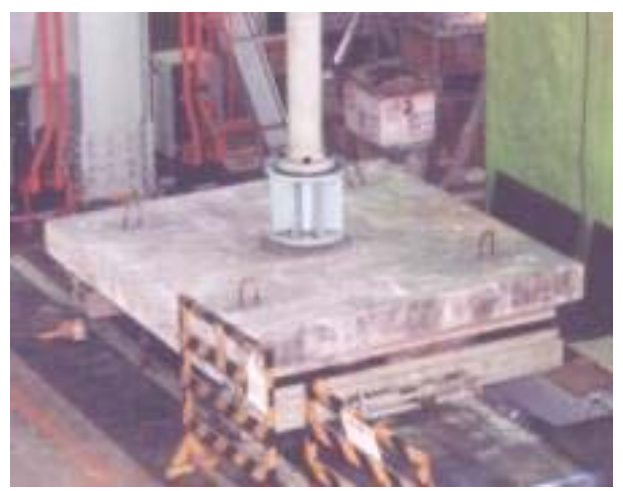

Figure 12 slab-type (two-directional sheet) dowel test [4] 


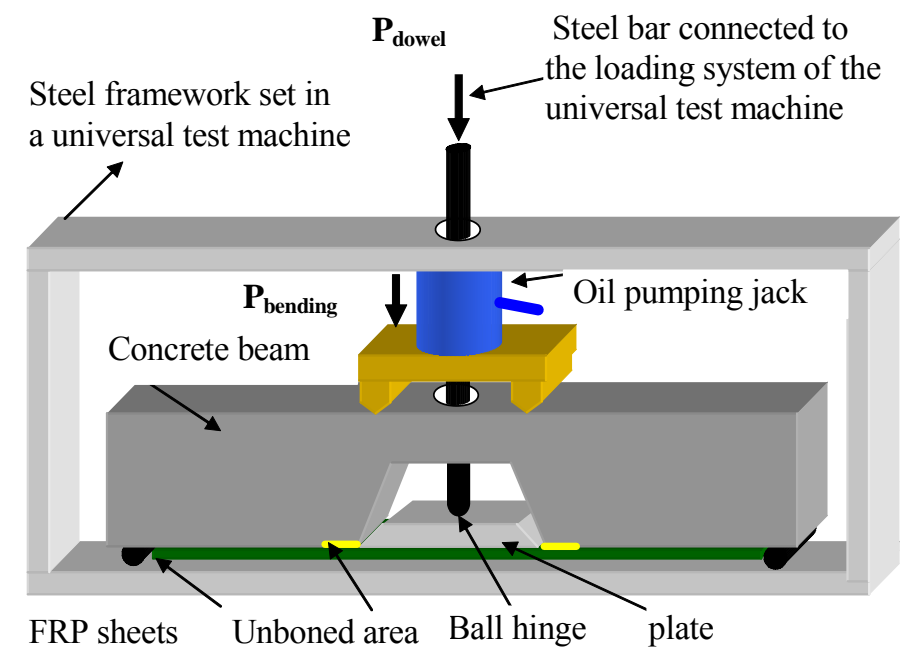

Figure 13 Mix-mode bond tests for FRP sheet-concrete interfaces

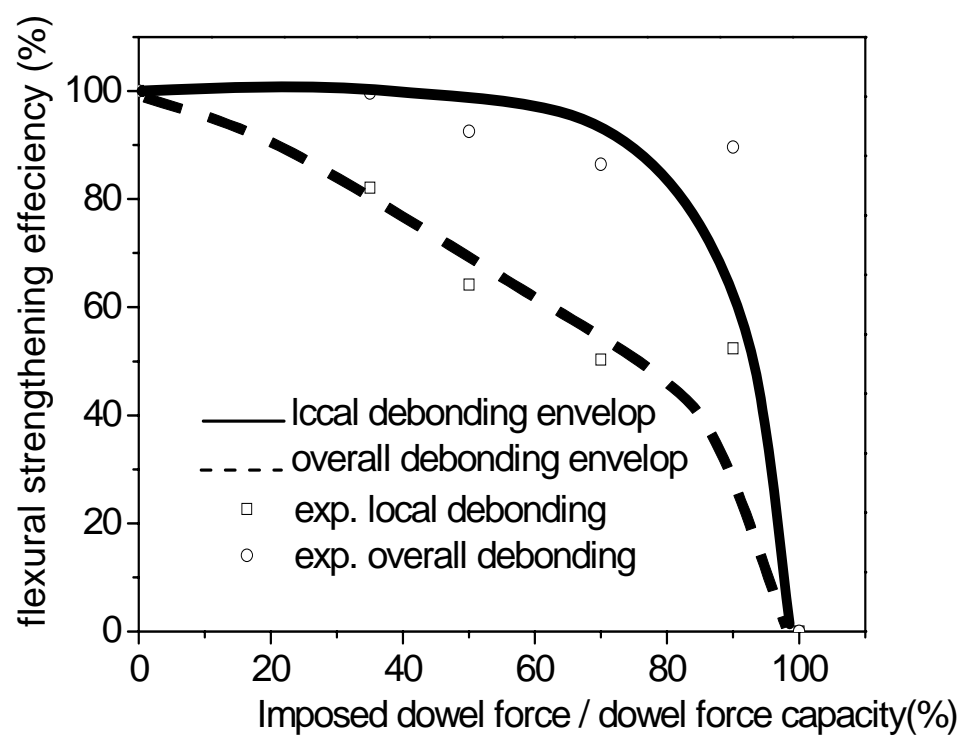

Figure 14 Effects of the dowel force on the shear force transfer on the interface shear stress transfer 


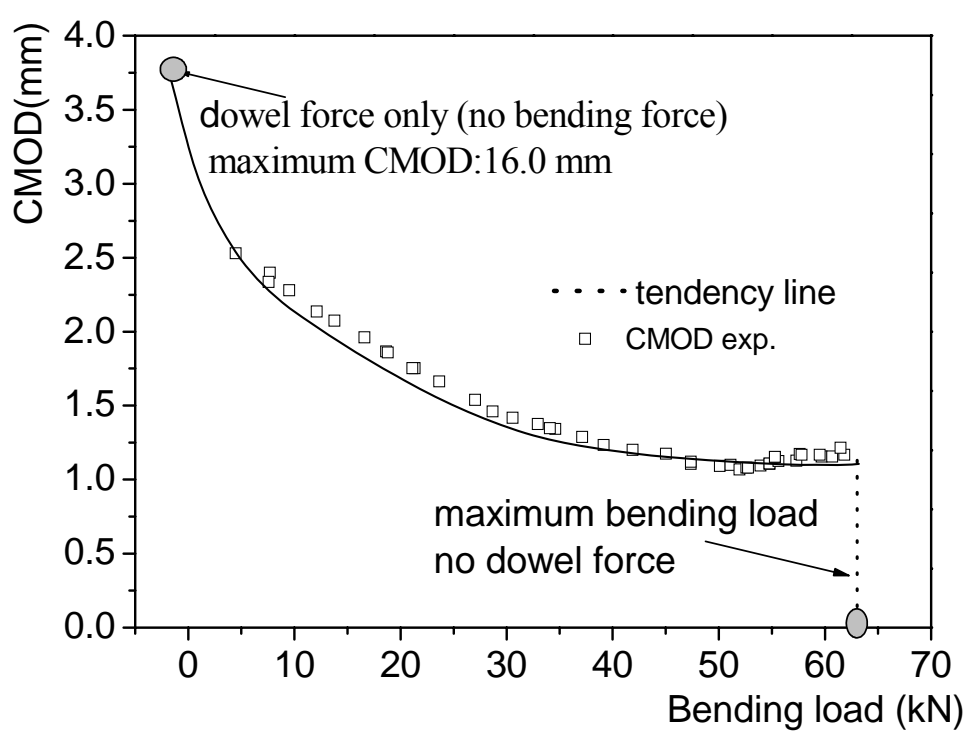

Figure 15 Change of vertical interface crack opening with the increase of tensile force in FRP sheets

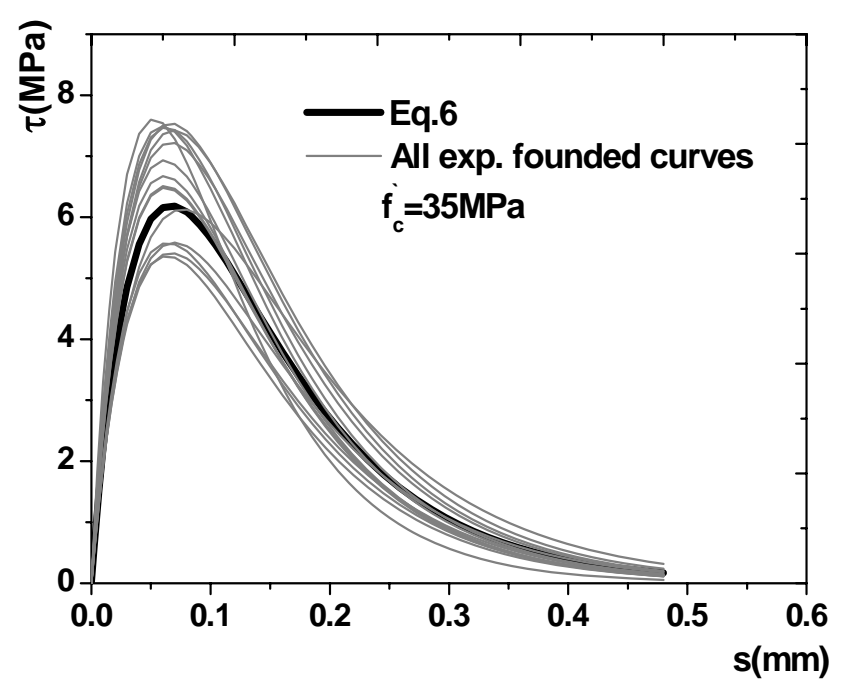

Figure 16 Proposed $\tau \sim s$ relationship for FRP sheet-concrete interfaces 


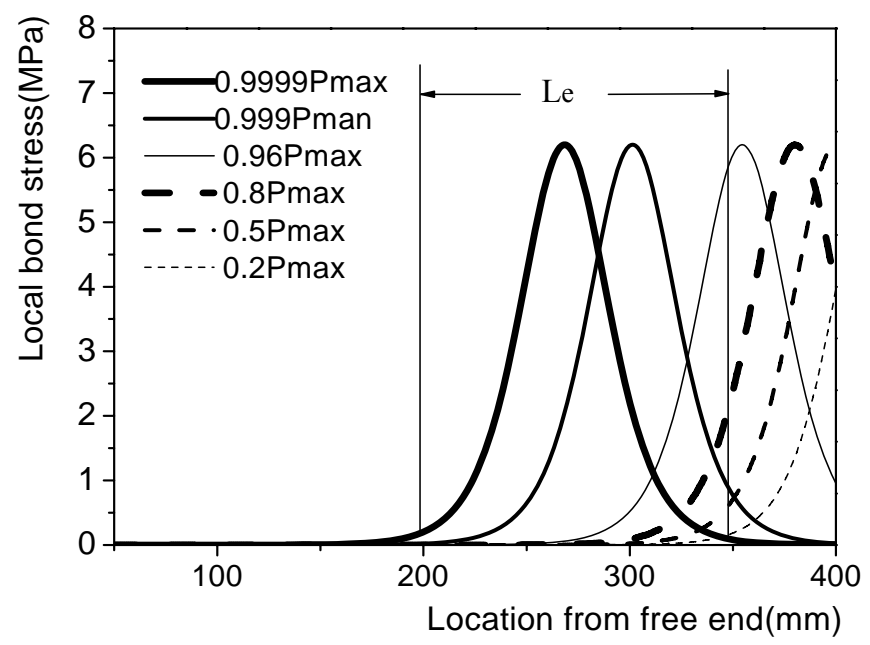

Figure 17 Definition of the effective bond length $L_{e}$

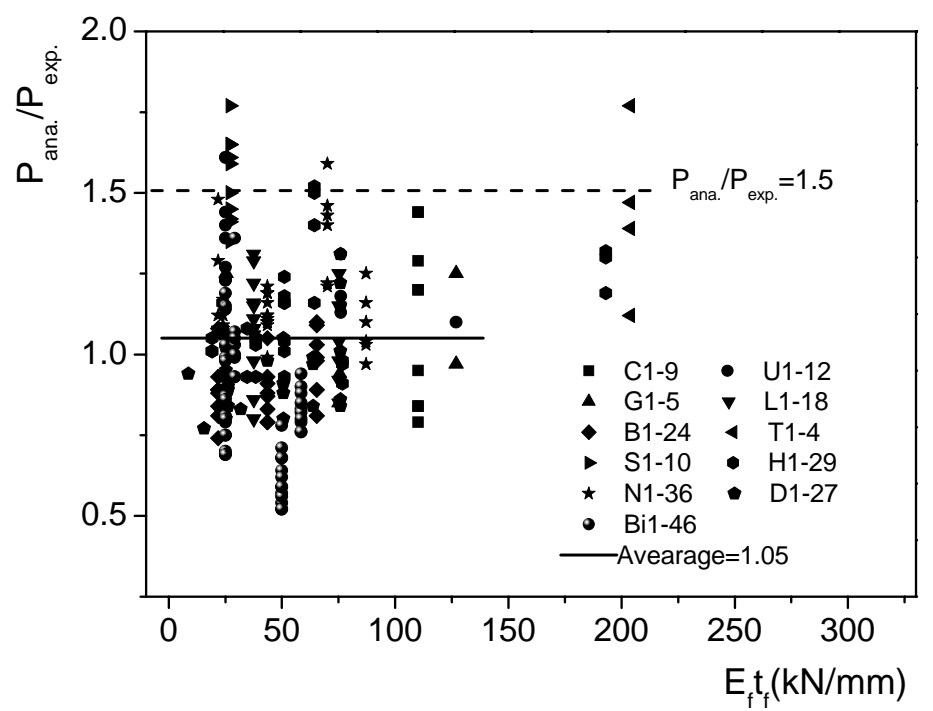

Note: $\mathrm{C} 1 \sim \mathrm{C} 9$ are from Chajes et al. [31]; U1 U12 are from Ueda et al. [24]; G1 G5 are from Garbriel et al. [56]; L1 L18 are from Lorenzis et al. [25]; B1 B24 are from Brosens et al.[27]; T1 T4 are from Täljsten [55]; S1 10 are from Sato et al. [29]; H1 H29 are from Yoshizawa et al.[30]; N1 36 are from Nakaba [26]; D1-D27 are from Dai et al.[34]; Bi1 46 are from Bizindavyi and Neale [23];

Figure 18 Large scatter of the bond strength of FRP sheet-concrete interfaces 


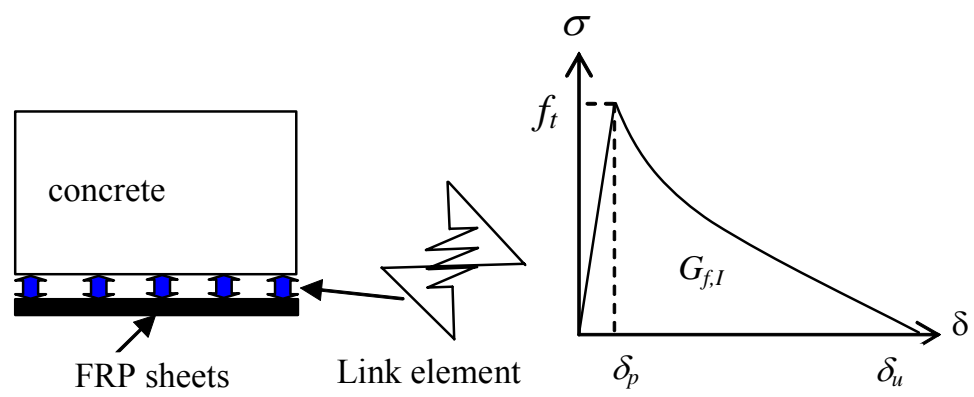

Figure 19 Modeling of the interface bond under tension

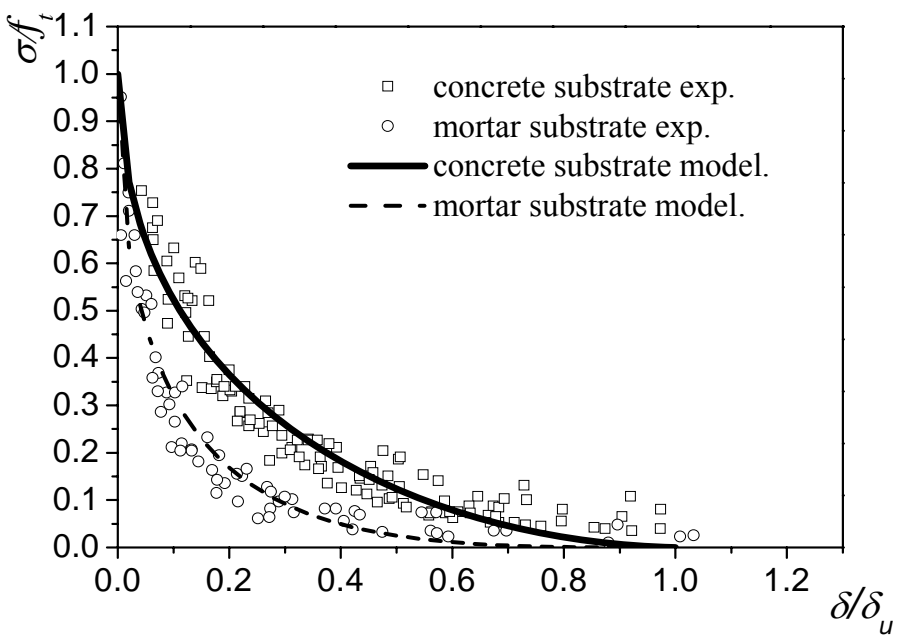

Figure 20 Tension softening diagrams of FRP sheet-concrete interfaces 


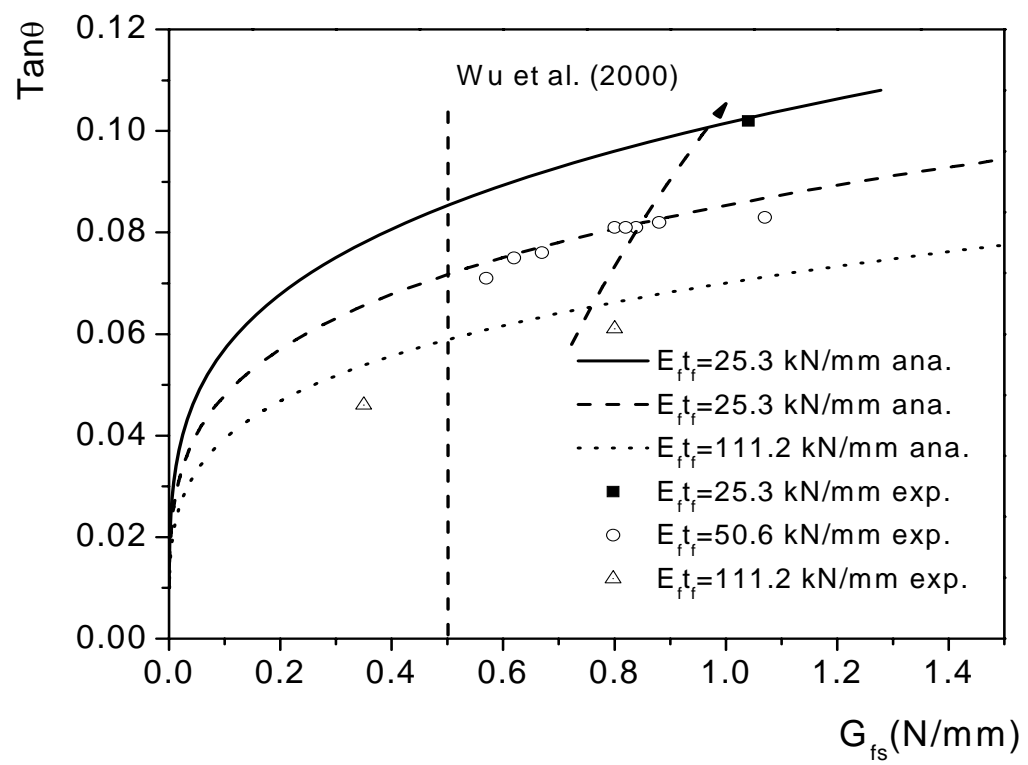

Figure 21 Relationship between peeling angle and the interface spalling fracture energy

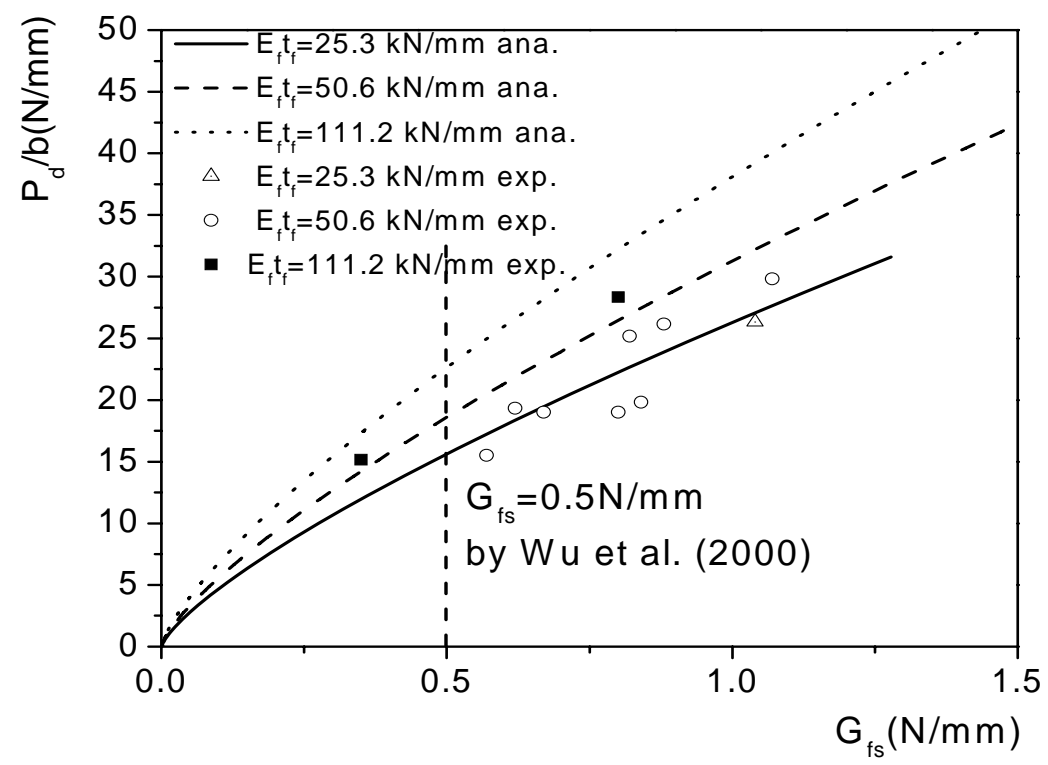

Figure 22 Relationship between dowel force capacity and the interface spalling fracture energy 
Fiber directions
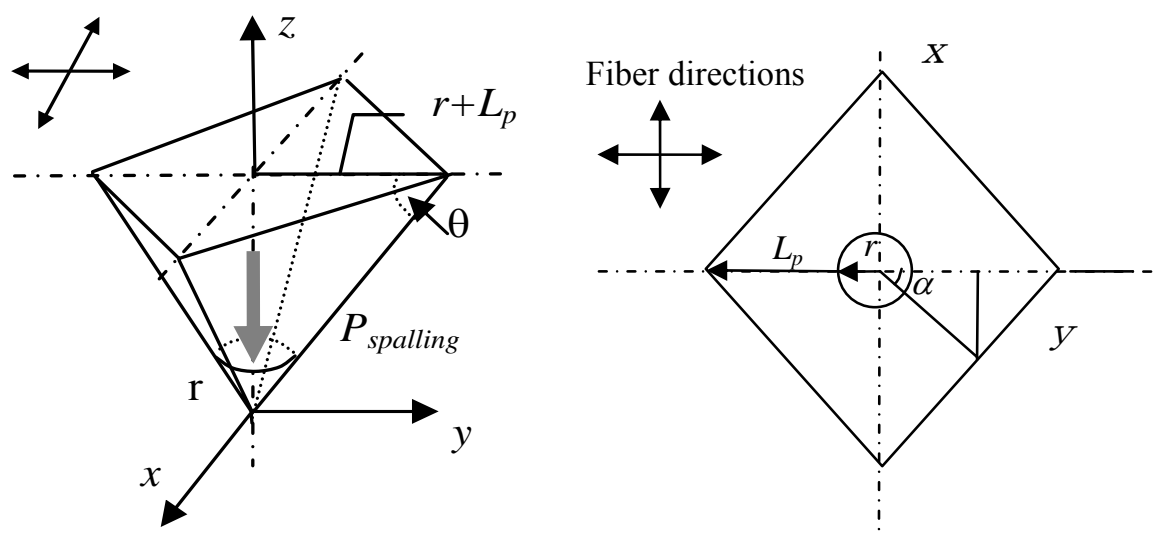

Figure 23 Spalling of FRP sheet-concrete interfaces in two dimensional retrofitting cases

Flexural Capacity $(\mathrm{kN}-\mathrm{m})$

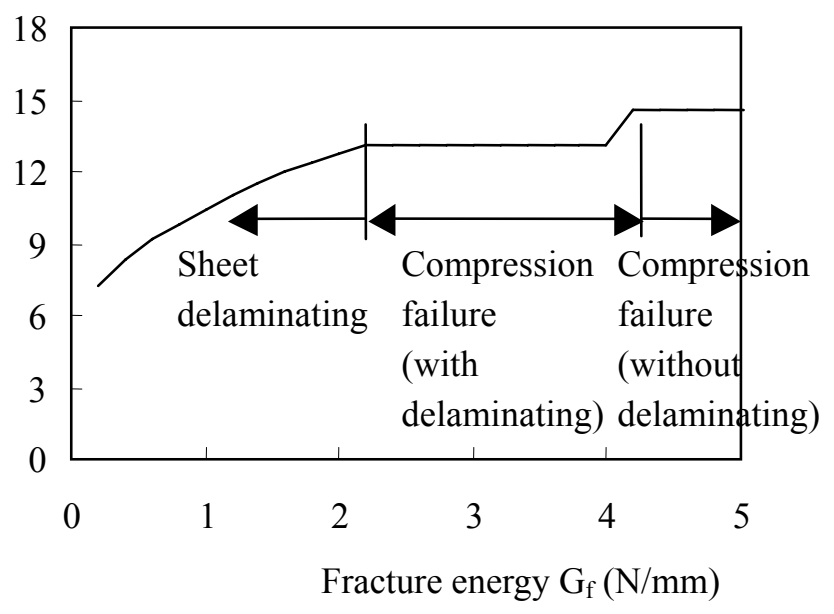

Figure 24 Effects of the interfacial fracture energy in FRP flexurally strengthened members

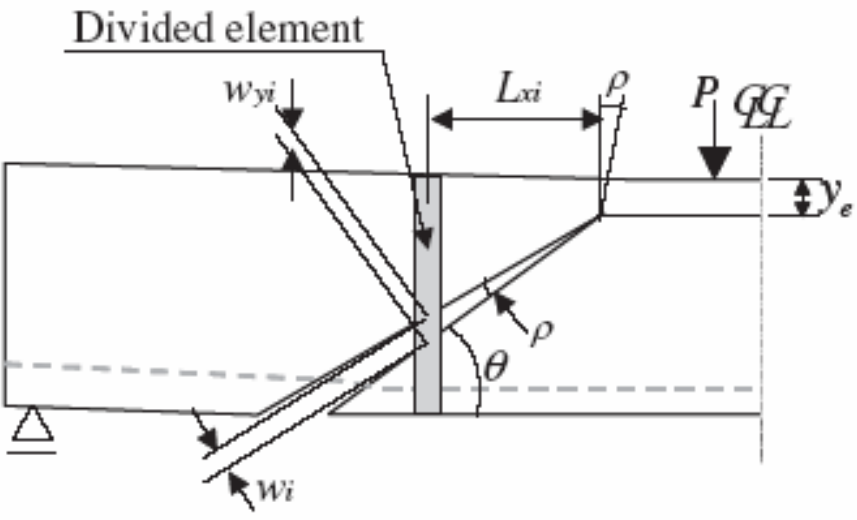

Figure 25 Rigid body model for predicting the shear capacity of FRP strengthened members 


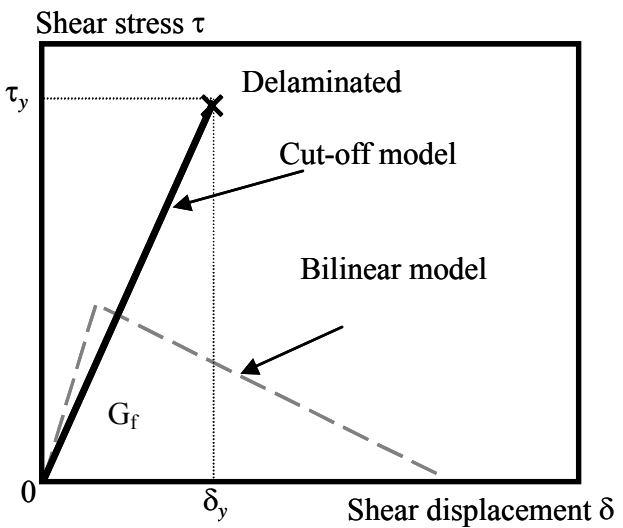

Figure 26 bond model used in Kamiharako's model

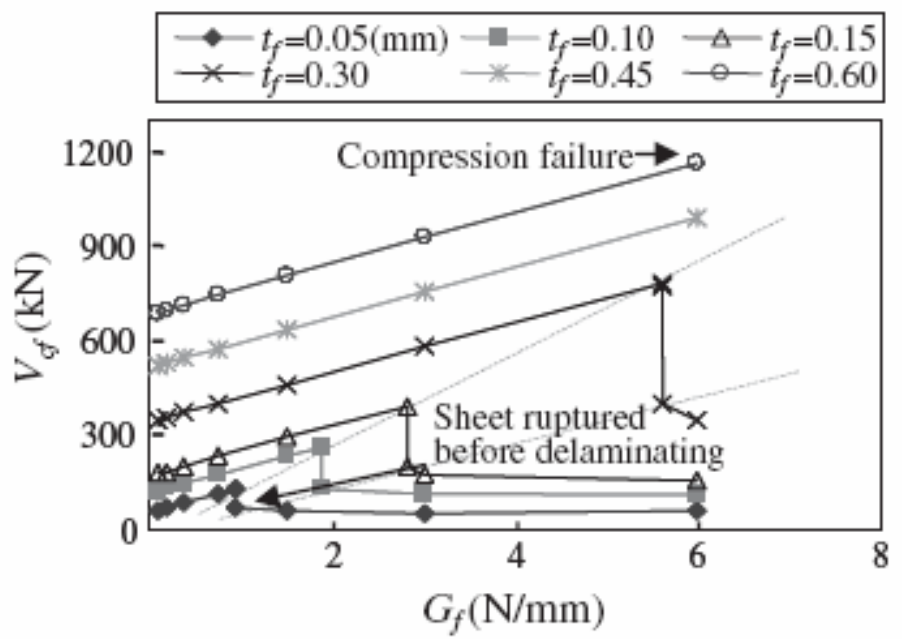

Figure 27 Effects of fracture energy on the shear capacity of strengthened members 


\section{Tables}

Table 1 Influencing factors on the bond of FRP sheet-concrete interfaces.

\begin{tabular}{|c|c|c|c|}
\hline & & & Influencing factor \\
\hline \multirow{5}{*}{ Mechanical } & \multicolumn{2}{|r|}{ Concrete } & $\begin{array}{l}\text { Modulus of elasticity, Thickness, Surface treatment, } \\
\text { Strength, Drying shrinkage, Water content }\end{array}$ \\
\hline & \multirow{4}{*}{$\begin{array}{l}\text { FRP } \\
\text { sheet }\end{array}$} & $\begin{array}{l}\text { Continuous fiber } \\
\text { sheet }\end{array}$ & $\begin{array}{l}\text { Modulus of elasticity, Strength, Thickness, Stiffness, } \\
\text { Length/width of sheet, Weave }\end{array}$ \\
\hline & & Bonding resin & \multirow{3}{*}{$\begin{array}{c}\text { Modulus of elasticity, Strength, Glass transition } \\
\text { temperature, Spread }\end{array}$} \\
\hline & & Primer & \\
\hline & & Putty & \\
\hline \multicolumn{3}{|c|}{ Environmental } & $\begin{array}{c}\text { Loading condition (bending, shearing, punching, cyclic), } \\
\text { Environmental actions (ambient temperature, moisture, } \\
\text { sun light radiation, etc.) }\end{array}$ \\
\hline
\end{tabular}

Table 2 Material parameters used in analysis for a flexural strengthening case

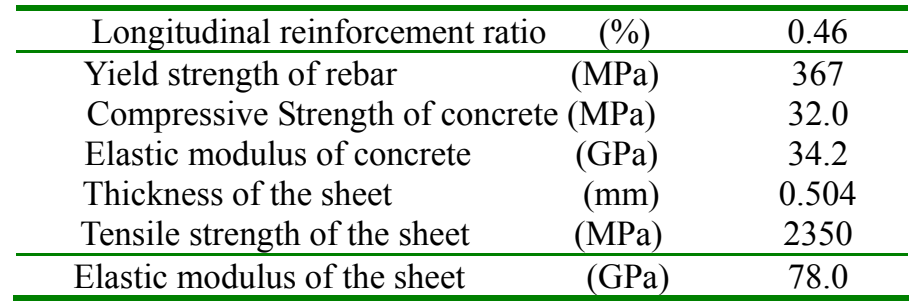

Table 3 Material parameters used in analysis for a shear strengthening case

\begin{tabular}{ccc}
\hline Total depth of beam & $(\mathrm{mm})$ & 350 \\
\hline Effective depth of beam & $(\mathrm{mm})$ & 300 \\
Strain capacity of concrete & $(\mu)$ & 2500 \\
Thickness of FRP sheets & $(\mathrm{GPa})$ & 34.2 \\
Thickness of the sheet & $(\mathrm{mm})$ & $0.05 \sim 0.6$ \\
Tensile strength of the sheet & $(\mathrm{MPa})$ & 3000 \\
Elastic modulus of the sheet & $(\mathrm{GPa})$ & 240 \\
Peak shear stress & $(\mathrm{MPa})$ & $0.94 \sim 60$ \\
\hline Peak slip & $(\mathrm{mm})$ & 0.2 \\
\hline
\end{tabular}

